\title{
Dynamics of ammonia exchange with cut grassland: synthesis of results and conclusions of the GRAMINAE Integrated Experiment
}

\author{
M. A. Sutton ${ }^{1}$, E. Nemitz ${ }^{1}$, C. Milford ${ }^{1, *}$, C. Campbell ${ }^{1}$, J. W. Erisman ${ }^{2}$, A. Hensen ${ }^{2}$, P. Cellier ${ }^{3}$, M. David ${ }^{3}$, \\ B. Loubet ${ }^{3}$, E. Personne ${ }^{3}$, J. K. Schjoerring ${ }^{4}$, M. Mattsson ${ }^{4, *}$, J. R. Dorsey ${ }^{5}$, M. W. Gallagher ${ }^{5}$, L. Horvath ${ }^{6}$,

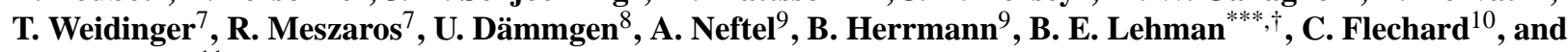 \\ J. Burkhardt ${ }^{11}$
}

${ }^{1}$ Centre for Ecology and Hydrology (Edinburgh Research Station) (CEH), Bush Estate, Penicuik, Midlothian, EH260QB, UK

${ }^{2}$ Energy research Centre of the Netherlands (ECN), Postbus 1, 1755 ZG Petten, The Netherlands

${ }^{3}$ Institut National de la Recherche Agronomique (INRA), UMR Environnement et Grandes Cultures, Thiverval-Grignon, 78850, France

${ }^{4}$ Plant and Soil Science Laboratory, University of Copenhagen (UoC), Faculty of Life Sciences, Thorvaldsensvej 40, 1871

Frederiksberg C, Copenhagen, Denmark

${ }^{5}$ School for Earth, Atmospheric and Environmental Sciences, University of Manchester (UoM), P.O. Box 88, Manchester, M60 1QD, UK

${ }^{6}$ Hungarian Meteorological Service (HMS), P.O. Box 39 1675, Budapest, Hungary

${ }^{7}$ Department of Meteorology, Eötvös Loránd University (ELU), Pázmány Péter sétány 1/A, P.O. Box 32,

1518 Budapest, Hungary

${ }^{8}$ Institut für Agrarökologie, Bundesforschungsanstalt für Landwirtschaft (FAL-D) (now the von Thunen Institute),

Bundesallee 50, 38116 Braunschweig, Germany

${ }^{9}$ Agroscope Reckenholz-Tänikon Research Station ART, (formerly FAL-CH) Reckenholzstrasse 191, 8046 Zürich, Switzerland

${ }^{10}$ Soils, Agronomy and Spatialization Unit, UMR-SAS, INRA, Rennes, France

${ }^{11}$ Institute for Crop Science and Resource Conservation, INRES-PE, University of Bonn, Karlrobert-Kreiten-Str. 13, 53115 Bonn, Germany

*now at: Institute of Earth Sciences “Jaume Almera”, CSIC, Lluis Solé i Sabarís, 08028, Barcelona, Spain

*** now at: Section for Economy \& Technology, Halmstad University, 30118 Sweden

${ }^{* * * *}$ formerly at: University of Bern (UoB), Bern, Switzerland

$\dagger$ deceased

Received: 21 October 2008 - Published in Biogeosciences Discuss.: 21 January 2009

Revised: 13 October 2009 - Accepted: 2 November 2009 - Published: 10 December 2009

\begin{abstract}
Improved data on biosphere-atmosphere exchange are fundamental to understanding the production and fate of ammonia $\left(\mathrm{NH}_{3}\right)$ in the atmosphere. The GRAMINAE Integrated Experiment combined novel measurement and modelling approaches to provide the most comprehensive analysis of the interactions to date. Major intercomparisons of micrometeorological parameters and $\mathrm{NH}_{3}$ flux measurements using the aerodynamic gradient method and relaxed eddy accumulation (REA) were conducted. These showed close agreement, though the REA systems proved insufficiently precise to investigate vertical flux
\end{abstract}

\section{Correspondence to: M. A. Sutton} (ms@ ceh.ac.uk) divergence. Grassland management had a large effect on fluxes: emissions increased after grass cutting $(-50$ to $700 \mathrm{ng} \mathrm{m}^{-2} \mathrm{~s}^{-1} \mathrm{NH}_{3}$ ) and after $\mathrm{N}$-fertilization (0 to $3800 \mathrm{ng} \mathrm{m}^{-2} \mathrm{~s}^{-1}$ ) compared with before the cut ( -60 to $40 \mathrm{ng} \mathrm{m}^{-2} \mathrm{~s}^{-1}$ ).

Effects of advection and air chemistry were investigated using horizontal $\mathrm{NH}_{3}$ profiles, acid gas and particle flux measurements. Inverse modelling of $\mathrm{NH}_{3}$ emission from an experimental farm agreed closely with inventory estimates, while advection errors were used to correct measured grassland fluxes. Advection effects were caused both by the farm and by emissions from the field, with an inverse dispersion-deposition model providing a reliable new approach to estimate net $\mathrm{NH}_{3}$ fluxes. Effects of

Published by Copernicus Publications on behalf of the European Geosciences Union. 
aerosol chemistry on net $\mathrm{NH}_{3}$ fluxes were small, while the measurements allowed $\mathrm{NH}_{3}$-induced particle growth rates to be calculated and aerosol fluxes to be corrected.

Bioassays estimated the emission potential $\Gamma=\left[\mathrm{NH}_{4}^{+}\right] /\left[\mathrm{H}^{+}\right]$for different plant pools, with the apoplast having the smallest values (30-1000). The main withincanopy sources of $\mathrm{NH}_{3}$ emission appeared to be leaf litter and the soil surface, with $\Gamma$ up to 3 million and 300000 , respectively. Cuvette and within-canopy analyses confirmed the role of leaf litter $\mathrm{NH}_{3}$ emission, which, prior to cutting, was mostly recaptured within the canopy.

Measured ammonia fluxes were compared with three models: an ecosystem model (PaSim), a soil vegetation atmosphere transfer model (SURFATM-NH $\mathrm{N}_{3}$ ) and a dynamic leaf chemistry model (DCC model). The different models each reproduced the main temporal dynamics in the flux, highlighting the importance of canopy temperature dynamics (Surfatm- $\mathrm{NH}_{3}$ ), interactions with ecosystem nitrogen cycling (PaSim) and the role of leaf surface chemistry (DCC model). Overall, net above-canopy fluxes were mostly determined by stomatal and cuticular uptake (before the cut), leaf litter emissions (after the cut) and fertilizer and litter emissions (after fertilization). The dynamics of ammonia emission from leaf litter are identified as a priority for future research.

\section{Introduction}

Compared with many other trace gases, such as carbon dioxide, sulphur dioxide and nitrous oxide, there are relatively few datasets that quantify biosphere-atmosphere exchange processes for ammonia. This is an important gap, since understanding the emission and fate of ammonia in the atmosphere is of fundamental importance for several global change issues (e.g., Erisman et al., 2008a, b). Firstly, emissions of ammonia represent a loss of valuable fertilizer nitrogen from farming systems. Once emitted, ammonia contributes to the formation of secondary particulate matter, reducing visibility, altering global radiative balance and providing a risk to human health (e.g., Amann et al., 2005; Davidson et al., 2005; Sutton et al., 2007). As a nitrogen compound, the deposition of ammonia back to land and water systems can substantially alter nutrient budgets. This provides a potential benefit increasing carbon sequestration in temperate and boreal forests, a matter of recent debate (e.g., Magnani et al., 2007; de Vries et al., 2008; Sutton et al., 2008b), as well as threats to biodiversity, through both the direct effects of ambient ammonia concentrations (Sutton et al., 2009c) and the indirect effects of enhanced nitrogen deposition (Achermann and Bobbink, 2003).

Fundamental to a better assessment of the fate of ammonia in the environment are improved data on biosphereatmosphere exchange. Although substantial progress has been made in the last two decades (see recent reviews: Hertel et al., 2006; Loubet et al., 2009a; Sutton et al., 2008a), most measurements of these processes have been conducted at separate research sites, with few intensive experiments designed to inter-compare measurement methods or develop a more holistic understanding of the interacting factors (e.g., Sutton et al., 2000; Misselbrook et al., 2005; Whitehead et al., 2008). To address this gap, the EU GRAMINAE project (GRassland AMmonia INteractions Across Europe, Sutton et al., 2001a) conducted an intensive experiment on ammonia exchange processes, held at the Bundesforschungsanstalt fur Landwirtschaft (FAL), Braunschweig during May-June 2000. The details of the strategy and implementation of the experiment are reported by Sutton et al. (2009a).

Here we summarize the achievements in relation to the key objectives of the Braunschweig Experiment. Drawing on the accompanying series of papers in this Special Issue, we highlight the main findings, developing an integrated picture of the measurement capability and the processes controlling ammonia biosphere-atmosphere exchange.

\section{Summary of the experimental outcomes}

Sutton et al. (2009a) summarized a set of five key questions and related these to a detailed list of scientific and technical objectives of the GRAMINAE experiment. Given the complex nature of the assessment and the large number of objectives, the key outcomes for each objective were summarized by Sutton et al. (2009b), indicating the extent to which the objectives were met (see their Table 1). In the following section, we highlight the key measurement-based findings of the experiment, followed by the interpretation emerging from the subsequent model analyses. At the end of the paper, we then summarize how the experiment helps answer the five main questions.

\section{Overview of the measurement results}

\subsection{Micrometeorology and surface energy budget}

The measurement foundation of the experiment was a detailed inter-comparison of turbulent exchange estimates (Nemitz et al., 2009b). Instrumentation from nine European institutions was applied to develop "consensus estimates" of each of the turbulent fluxes and components of the energy balance with a $15 \mathrm{~min}$ time resolution from 19 May to 15 June 2000.

The inter-comparison of Nemitz et al. (2009b) highlights how uncertainty in individual estimates of sensible and latent heat fluxes would normally propagate to uncertainty in trace gas fluxes in most studies where replicated measurements are not available. For example, the mean relative standard deviation of individual $15 \mathrm{~min}$ estimates of the friction velocity $\left(u_{*}\right)$ was $14 \%$, while the values for sensible $(H)$ and latent $(\lambda E)$ heat flux were $58 \%$ (equivalent to $14 \mathrm{~W} \mathrm{~m}^{-2}$ ) 


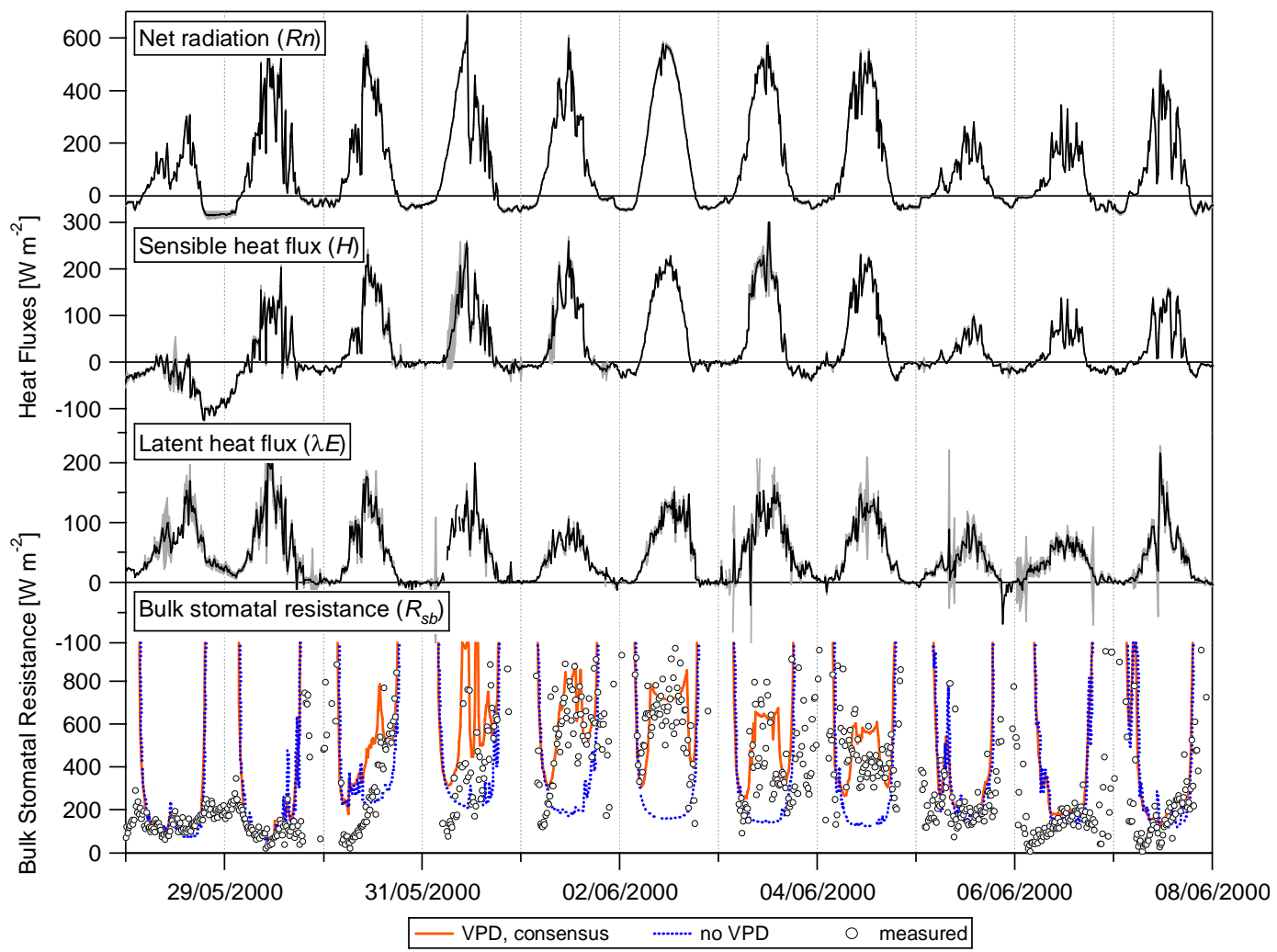

Fig. 1. Illustration of the time course of heat fluxes $(\mathrm{Rn}, \mathrm{H}, \lambda \mathrm{E})$ and canopy bulk stomatal resistance $\left(\mathrm{R}_{s b}\right)$ through changing conditions during the GRAMINAE experiment. The error bounds in the heat fluxes (shaded in grey) are \pm standard deviation of independent estimates. For $\mathrm{R}_{s b}$, the measured values (points) are compared with a model fit based on total solar radiation and canopy Leaf Area Index (blue line), and with a model fit that also includes the effect of moisture limitation according to vapour pressure deficit (red line).

and $25 \%\left(21 \mathrm{~W} \mathrm{~m}^{-2}\right)$, respectively. The median relative standard deviation in net radiation $(R n)$ was $4 \%\left(7 \mathrm{~W} \mathrm{~m}^{-2}\right)$. The high relative standard deviation for the sensible heat flux is related to the bi-directional nature of the fluxes as well as the uncertainties occurring under stable atmospheric stratification. The relative standard deviations of average fluxes for the overall experiment were smaller, at $2 \%, 8 \%$, $18 \%$ and $6 \%$ for friction velocity, sensible heat, latent heat and net radiation, respectively (Nemitz et al., 2009b). The results imply that for $u_{*}$ and $H$, the main uncertainty is due to spatial heterogeneity in surface and turbulence, rather than systematic differences between approaches, and hence an ensemble average provides a more robust 15 -min value than can be derived with a single setup.

Even with such an extensive inter-comparison, the energy balance was only $80 \%$ closed. Nemitz et al. (2009b) suggest that this may be explained by omission of low turbulence contribution by $15 \mathrm{~min}$ averaging and methodological limitations of the eddy covariance method. In addition, uncertainties in net radiation, such as sensor bias or spatial differences between the sampled area and the flux footprint may contribute to differences. While such nonclosure of the energy balance is typical (e.g., Laubach and Teichmann 1999; Wilson et al., 2002), the associated uncertainties do not directly propagate to the calculation of ammonia fluxes (assuming that friction velocity is estimated reliably). However, these uncertainties have the potential to affect interpretation of the measured ammonia fluxes. In particular, an underestimation of latent heat flux would result in overestimation canopy scale stomatal resistances, as used in subsequent model analysis (Burkhardt et al., 2009; Meszaros et al., 2009). While recognizing these uncertainties, the combined "consensus" dataset provided a well characterized estimation of the turbulent exchange fluxes, including temporal variation in uncertainty as shown in Fig. 1. Comparison of friction velocity and sensible heat flux derived from profiles of wind and temperature, respectively, with their eddy-covariance estimates, shows encouraging agreement, but some underestimation in nighttime underestimation of sensible heat. This might indicate limitations of the stability correction used in the flux-gradient relationship and may have led to a nighttime underestimation of gradient-derived fluxes of other compounds $\left(\mathrm{NH}_{3}, \mathrm{HNO}_{3}\right)$.

Figure 1 also shows measurement-based estimates of canopy stomatal resistance with a fitted parameterization 
based on the Jarvis (1976) formulation, with and without consideration of the effects of water stress in the modelled resistances (Nemitz et al., 2009b). The comparison highlights the moisture limitation of the grass between 30 May and 5 June, which was linked to high surface temperatures (Sutton et al., 2009a). There was thus a clear temporal interaction of environmental conditions with management of the grassland, which was cut on the morning of 29 May and fertilized with ammonium nitrate on the morning of 5 June. In particular, the reduction of the grass canopy (cut from $0.76 \mathrm{~m}$ to $0.07 \mathrm{~m}$ ), further decreased the transpiration rate and exposed the ground surface. All together, these changes allowed the canopy and soil surface temperatures to increase from daily maxima of 15 to $25^{\circ} \mathrm{C}$, prior to the cut, to maximum daily values of 30 to over $40^{\circ} \mathrm{C}$ between 31 May to 4 June. These surface differences need to be considered when interpreting the measured ammonia fluxes, since increased temperature is expected to favour ammonia volatilization (see Sect. 4).

\subsection{Farm ammonia emissions and advection effects}

One of the challenges in quantifying ammonia exchange fluxes with different land types is the fact that most of the emission sources are ground-based and occur in rural landscapes alongside sink areas (e.g., Duyzer et al., 2001; Dragosits et al., 2002). The consequence is that "ideal" micrometeorological conditions (large homogeneous fetch, no horizontal gradients in ammonia concentrations) tend to be a rarity for ammonia for many European landscapes. This heterogeneity can have two effects: firstly, advection may cause errors in measured vertical fluxes, with a divergence of the vertical flux measured at a height $z$ above the canopy compared with the flux at the canopy level $\left(F\left(z_{o}^{\prime}\right)\right.$, Loubet et al., 2001, 2006); secondly, this combination of horizontal and vertical dispersion effects can affect the spatial pattern and magnitude of dry deposition to different canopies (Milford et al., 2001a; Loubet et al., 2006).

The spatial context of the Braunschweig Experiment provided suitable conditions to investigate these landscapelevel interactions. A potential constraint was that advection effects would dominate the vertical fluxes and therefore prevent analysis of ammonia surface exchange. Prior modelling of these effects was therefore made before selecting the field site (Sutton et al., 2009a), and this showed that, with measurements made a sufficient distance from an adjacent livestock farm $(550 \mathrm{~m}, 750 \mathrm{~m})$, the advection effects would be sufficiently large to detect, but be small enough to represent an appropriate correction in flux estimates. With the livestock farm situated directly to the west of the main field (Site 1, see map of Sutton et al., 2009a), such effects would also be limited to conditions with winds from between $\sim 250^{\circ}-290^{\circ}$.

To address these interactions, the experiment focused on measurements to: a) quantify ammonia emissions from the buildings of the livestock farm (Hensen et al., 2009a), b) use these results, together with measurements of horizontal ammonia gradients across the site, to quantify advection effects (Loubet et al., 2009b), and c) apply these estimates when relevant to correct measured exchange fluxes (Milford et al., 2009).

The analysis reported by Hensen et al. (2009a) applied three dispersion modelling approaches based on ammonia concentration measurements $\sim 230 \mathrm{~m}$ downwind of the farm buildings (Site 3, Sutton et al., 2009a) to quantify the ammonia emissions from the farm. They compared the results obtained with two 3-dimensional models, the Gaussian and the Huang 3-D model. A 2-dimensional localscale dispersion and deposition model (FIDES-2-D) was used to assess the uncertainty related to deposition between the farm houses and the measurement locations. The 3-D models were used to estimate emissions from the measured concentrations using (inverse dispersion method). In parallel, ammonia emissions were calculated according to the usual inventory methodology based on livestock numbers and emission factors (Döhler et al., 2002). As the site represents a complex mix of animal types and farm buildings (including naturally ventilated cattle housing), such a comparison is expected to be challenging.

Hensen et al. (2009a) found encouragingly close agreement between the dispersion modelling approaches and the inventory estimates. Overall, the Gaussian model indicated emissions of $9.2 \pm 0.7 \mathrm{~kg} \mathrm{NH}_{3} \mathrm{day}^{-1}$ for all the buildings compared with $6.4 \pm 0.18 \mathrm{~kg} \mathrm{NH}_{3} \mathrm{~d}^{-1}$ (Huang 3-D model) model and $9.6 \mathrm{~kg} \mathrm{NH}_{3}$ day $^{-1}$ based on the standard German inventory approach (Döhler et al., 2002). Key uncertainties were found to be the assumptions made about dry deposition between the farm buildings and the ammonia measurement location (Site 3). Incorporating dry deposition into the FIDES-2-D model (which would require an additional source to maintain the same ammonia concentrations at Site 3), led to a larger emission estimate of $8.7 \mathrm{~kg} \mathrm{NH}_{3}$ day $^{-1}$. Given that an independent estimate of ammonia emissions from cattle (Demmers et al., 1999) is around 14\% less than the values of Döhler et al. (2002), it can be seen that the inverse dispersion estimates reflect the overall uncertainties.

One of the findings of Hensen et al. (2009a) was a clear diurnal pattern in the farm ammonia emissions. Figure 2 summarizes these differences, showing that larger emissions during the day are correlated with increased convectivemixing, as indicated by the modeled vertical exchange velocity, though increased temperature may also have played a role.

When operated in forward mode (i.e., calculating concentrations from estimated emissions), the FIDES-2D model also allowed horizontal ammonia concentration profiles to be simulated across the study field and compared with measurements (Loubet et al., 2009b). Figure 3 illustrates horizontal profiles in ammonia for three periods: 


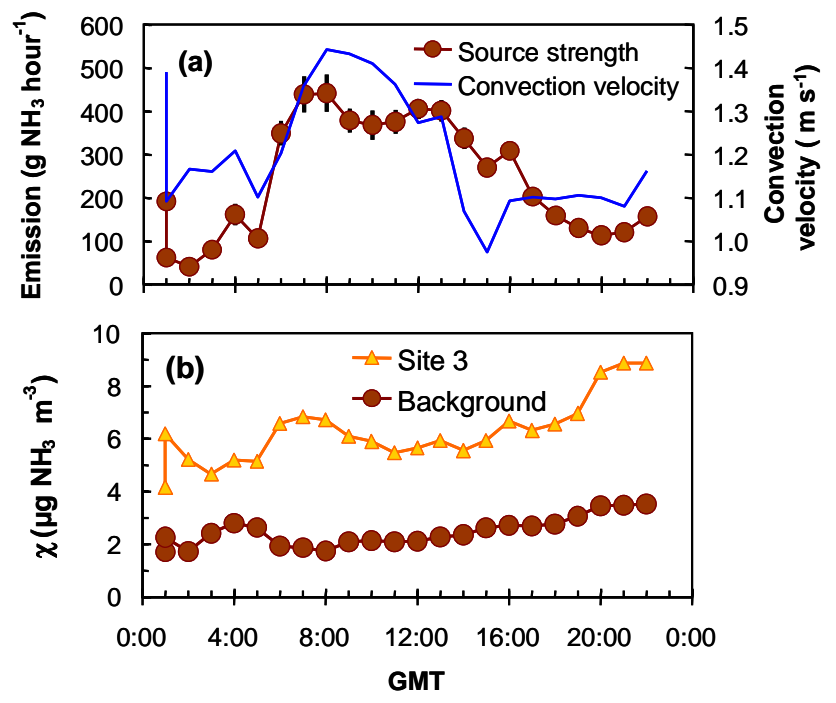

Fig. 2. (a) Diurnal variation in $\mathrm{NH}_{3}$ emission from the farm buildings estimated with Huang-3-D (circles, error bars are 95\% confidence limits), and convective velocity (triangles); (b) background concentration (Site 6) and concentration downwind of the farm (Site 3). Data are averaged for $\pm 15^{\circ}$ of the farm wind sector. Convective velocity is a measure of the free and force convective transfer between the inside and the outside of the building.

25 May 11:45 Greenwich Mean Time (GMT), before the field was cut; 2 June 23:45 GMT, after the field was cut; and 7 June 09:45, after the field was fertilized with ammonium nitrate. As will be seen in the following section, ammonia emissions from the field itself influenced the air, enriching ammonia concentrations above it, especially after fertilization. Thus for the first period illustrated in Fig. 3, ammonia concentrations decreased away from the farm as a result of dispersion and dilution. By contrast, for the third period, and to some extent the second period, concentrations first decreased away from the farm, then increased again over the fertilized field.

These interactions have consequences for the estimation of advection errors in the ammonia surface exchange fluxes, which result from the effect of changing air concentration $\left(\chi_{a}\right)$ with distance $(x)$ in the downwind direction $\left(d \chi_{a} / d x \neq 0\right)$. Loubet et al. (2009b) show that both positive and negative advection errors in vertical ammonia fluxes occur depending on whether there was a net concentration decrease (dominated by dispersion away from the farm), or a net concentration increase (driven by emissions from the field itself). Loubet et al. (2009b) found a close agreement between modelled and measured values of the advection error, including both advection as being mainly due to the farm dispersion (positive values) and mainly due to emission from the field itself (negative values). Overall, the resulting advection corrections (at
$550 \mathrm{~m}$ ) typically amounted to 5-50\% of the uncorrected fluxes for the period prior to the cut (for periods when the field was downwind of the farm), $2-10 \%$ following the cut and $1-10 \%$ for the period following fertilization (Loubet et al., 2009b; Milford et al., 2009). A sensitivity analysis performed with FIDES-2-D moreover shows that advection errors due to field emissions become significant (larger than $10 \%$ ) at $1 \mathrm{~m}$ height for fetches lower than $100 \mathrm{~m}$ under typical grassland conditions.

\subsection{Determination of net vertical ammonia fluxes with the grass canopy}

Several methods for estimating net vertical ammonia exchange fluxes with the grass field were applied. The reference approach used during the experiment was the aerodynamic gradient method (AGM), implemented using four independently operated continuous ammonia detectors. Three of these were implementations of the continuous wetrotating "AMANDA" system of Wyers et al. (1993), while the fourth used a system of mini-wet effluent diffusion denuders (mini-WEDD, Neftel et al., 1999). Two of the AMANDAs and the mini-WEDD were located at Site 1 (550 $\mathrm{m}$ from the farm), with the third AMANDA located at Site 2 ( $750 \mathrm{~m}$ from the farm).

The inter-comparison of these systems is reported by Milford et al. (2009). Overall, no clear evidence was found of differences in the behaviour of ammonia fluxes across the field (between Sites 1 and 2), though the advection corrections resulting from dispersion from the farm were smaller for the latter site. The most challenging feature of this analysis was the temporally variable performance of the instruments, which were found to agree well on some days and disagree substantially on other days. Milford et al. (2009) illustrate the comparison of measured fluxes for several days during each of the three measurement periods (pre-cut, post-cut, post-fertilization). Small surface fluxes $\left(F\left(\mathrm{z}_{o^{\prime}}\right)\right)$ prior to the cut were rather uncertain, but were

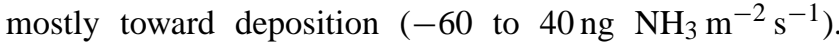
During this period, the individual systems often varied between $10-50 \%$ of the flux. Similar discrepancies were found for the post-cut period, with fluxes in the range -50 to $700 \mathrm{ng} \mathrm{m}^{-2} \mathrm{~s}^{-1}$. For the period following fertilization large emission fluxes were observed ( 0 to $3800 \mathrm{ng} \mathrm{m}^{-2} \mathrm{~s}^{-1}$ ), but, while some days showed excellent agreement (estimates within 10-20\%), on other days the instruments indicated fluxes varying by a factor of 5 (e.g., 8 June).

Milford et al. (2009) implemented a detailed protocol to filter the measured flux datasets including restrictions for periods of micrometeorological uncertainty (especially stable nocturnal conditions), excluding disturbed wind sectors, and gap-filling to handle periods when individual instruments failed or were being calibrated. They then combined the dataset to estimate ammonia concentrations and fluxes based on the "mean gradient" of the four systems. 


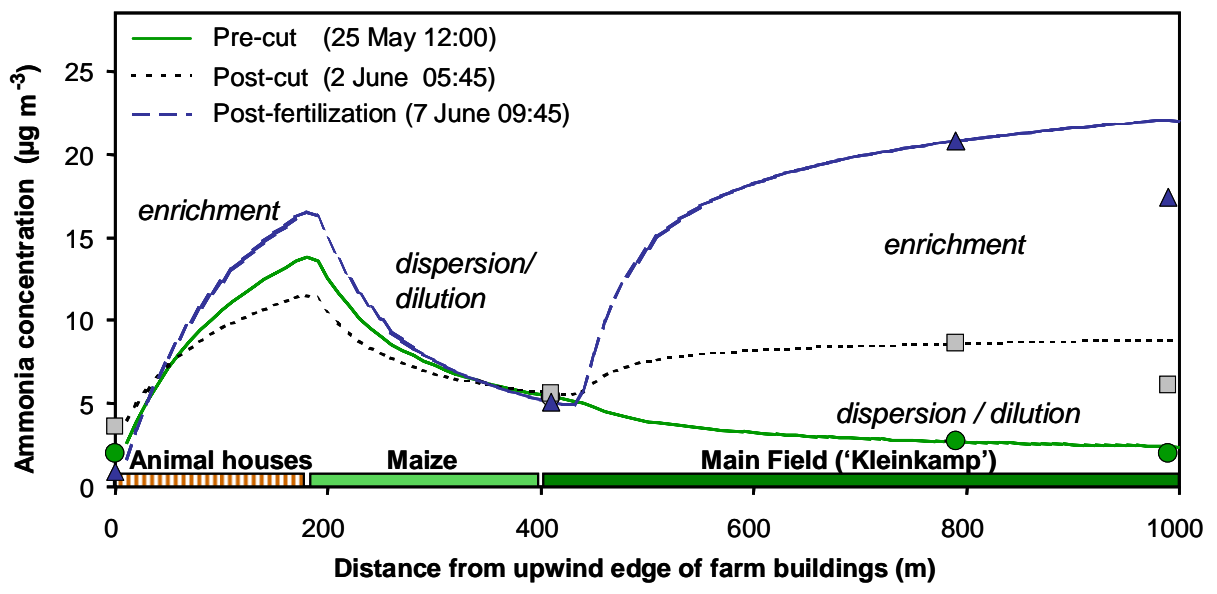

Fig. 3. Example horizontal gradients of $\mathrm{NH}_{3}$ concentration across the Braunschweig field site, with distance from a group of farm buildings (for site map see Sutton et al., 2009a). Measurements at Sites 1, 2 and 3 are compared with simulations using the FIDES-2-D approach (Loubet et al., 2009b). The three model runs refer to pre-cut (25 May 2000), post-cut (2 June 2000) and post-fertilization periods (7 June 2000). The concentrations at site $3(230 \mathrm{~m})$ are similar so that the points overlay each other.

For most periods, it was apparent that this was a valid approach, giving equal weight to the different measurement systems. However, for four days (3 June, 8-10 June), there were indications that two of the denuder systems might be over-reading concentrations (e.g., loss of calibration), and wide divergence from the other two systems. As there was some ambiguity in removing these systems from the flux estimate, Milford et al. (2009) also calculated the mean of the two remaining systems for these periods as an "alternative gradient" flux (see Fig. 4). In addition to instrument uncertainties, the discrepancy could be related to spatial heterogeneity in the fertilizer application, although this would not explain why the estimates agreed on other days. Formally, the mean gradient $\left(F_{m g}\right)$ estimates provide the reference flux estimates. However, the alternative gradient flux $\left(F_{a g}\right)$ is used to inform the model analysis and the inter-comparison with other flux measurement approaches. Comparison with other flux measurement methods (see below) was used to provide an independent assessment of whether $\mathrm{F}_{m g}$ or $\mathrm{F}_{a g}$ was the more robust estimate on each of the days concerned.

The measurement inter-comparison highlights the high uncertainty in quantifying ammonia fluxes. While recognizing the particular uncertainties for the 4 days noted, the overall dataset probably represents the most rigorously quantified period of ammonia exchange fluxes with the land surface that is currently available. Although new flux measurement methods have since begun to be used for ammonia, such as eddy covariance using tunable diode later absorption spectroscopy, these approaches remain uncertain below $\sim 50 \mathrm{ng} \mathrm{m}^{-2} \mathrm{~s}^{-1}$ (Famulari et al., 2004; Whitehead et al., 2008) and would require significant cost reductions before becoming more widely used for $\mathrm{NH}_{3}$ flux measurement.
Two alternative methods were applied to estimate ammonia fluxes during the experiment: the REA method and an inverse dispersion method using the FIDES-2-D model.

Hensen et al. (2009b) report the inter-comparison of four continuous REA methods, three of which were developed specifically for the GRAMINAE analysis. Several chemical detection methods were applied, including parallel-plate denuders, a membrane diffusion system and two miniWEDD approaches (see Hensen et al., 2009b). The REA approach allows fast response switching between up and down drafts combined with slow response (e.g., 2-5 min) detectors, providing an approach that can determine fluxes from measurements at one height. Thus, in principle, deployment of the instruments at several heights could be used directly to determine vertical flux divergence. The main reason that this turned out not to be possible was the higher analytical precision required for REA measurement of fluxes compared with the AGM: typically the concentration difference between up and down drafts is of the order of 5 times smaller than the equivalent difference in over the mean vertical profile above short vegetation (Sutton et al., 2007; Hensen et al., 2009b). With the REA systems, it was possible to implement an auto-referencing mode of operation, e.g., random switching between denuders, which was used identify and to correct for concentration biases (Nemitz et al., 2001a; Hensen et al., 2009b). Using this approach, it was in some cases possible to maintain a precision approaching that of the AGM implementations.

Loubet et al. (2009b) describe a new application of the FIDES-2-D model to estimate the net ammonia flux. In this approach the flux is estimated with the dispersion model by combining estimates of vertical diffusivity from measured $u_{*}$ with the near-surface concentration enhancement above (or below) background as a means to estimate the flux. The 

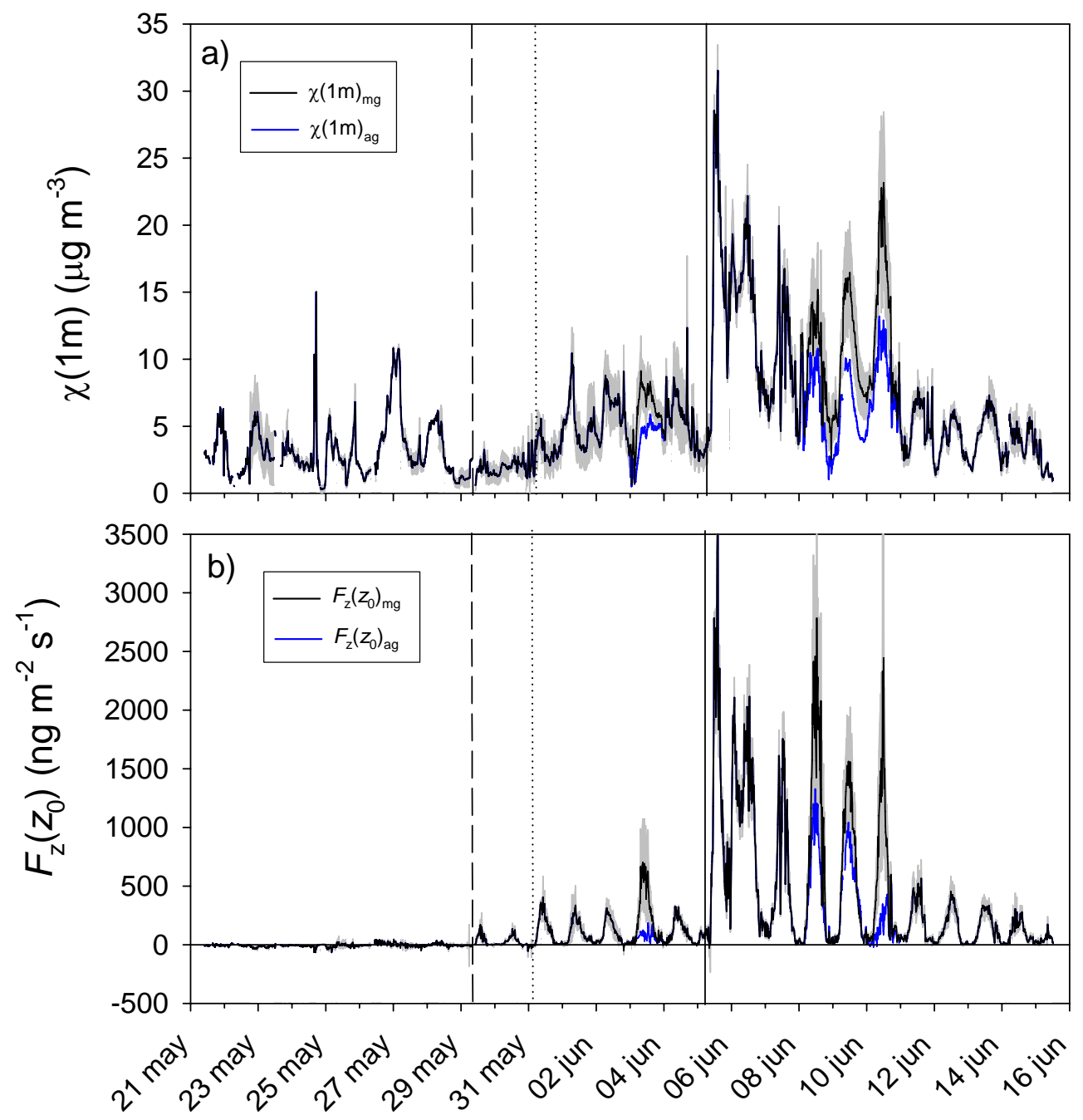

Fig. 4. Graph showing the reference "mean gradient" (mg) estimates of ammonia concentration $(\chi(1 \mathrm{~m}))$ and ammonia flux at the surface $\left(\mathrm{F}\left(z_{o}\right)\right)$ measured above the main field during the GRAMINAE experiment ( \pm standard errors, in grey). During 3 June and 8-10 June, extreme instrument uncertainty led to an "alternative gradient" (ag) being calculated, based on two of the four systems. The vertical bars show the times of cutting (29 May) removal of the grass cuttings (30/5) and fertilization (5 June).

attractiveness of this method is that it depends only on the mean $\mathrm{NH}_{3}$ concentration (e.g., at $1 \mathrm{~m}$ above the canopy) rather than estimation of small vertical concentration gradients in the surface layer or small differences between up- and down-draughts of air, as in the REA approach. In principle the FIDES-2-D approach is therefore less sensitive to measurement error. By contrast, a disadvantage of this method is that it requires continuous measurement of the background atmospheric $\mathrm{NH}_{3}$ concentration. In the Braunschweig Experiment, this was available from hourly measurements using a wet-rotating denuder (Keuken et al., 1988) deployed at $43 \mathrm{~m}$ (Site 6, see map in Sutton et al., 2009a). Although relatively easy to operate this system, we recognize that such background sampling would not be feasible in many studies.
The flux estimates from the three measurement approaches (AGM, REA and FIDES) are shown together in Fig. 5. For the purpose of this comparison, the "mean gradient" estimate of the AGM (up to 4 systems) is shown with the mean from the REA (up to 4 systems), and the results from the FIDES model/measurement approach. The latter is based on the near-surface and background ammonia concentrations (Site 1, 1 m; Site 6, 43 m), and continuous estimation of the fetch according the field size and winddirection. Given the nearly complete independence of the three approaches, the agreement between the flux estimates is extremely encouraging for certain days $(1,2,4,6,9$ and 13 June), while other days showed clear discrepancies, such as the 3, 8 and 10 June, the days for which there was significant uncertainty between $F_{m g}$ and $F_{a g}$. 

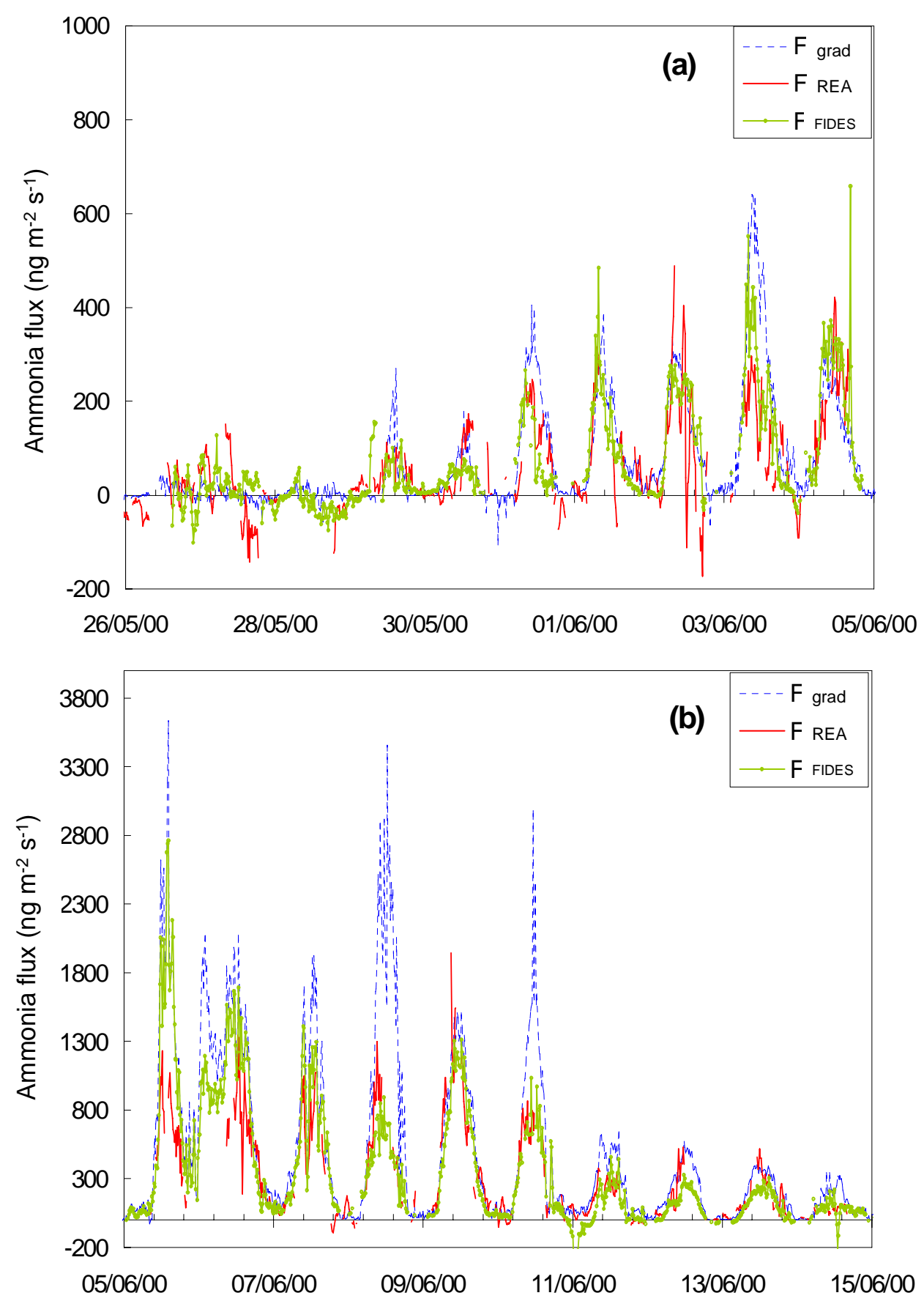

Fig. 5. Ammonia flux estimated using three independent approaches: (a) the pre-fertilization period, and (b) the post-fertilization period. The comparison shows the aerodynamic gradient method (mean of up to 4 systems), the REA method (mean of up to 4 systems) and the FIDES-2-D inverse dispersion model using measured background $\mathrm{NH}_{3}$ concentration (43 m, Site 6), mean $\mathrm{NH}_{3}$ concentration (1 m, Site 1) and fetch over the field.

For the period before fertilization, Fig. 5 shows the REA method to be the most scattered of the flux estimates (suggesting that it is the least precise), while directly after fertilization (5 June) the REA estimates read low, which is thought to be due to incomplete capture of the high fluxes at this period (e.g., possibly linked to light easterly winds, or with a tendency to partly saturate some of the REA inlet systems during periods of high ammonia concentrations, Hensen et al., 2009b). The close agreement of the FIDES estimate of the flux with the REA estimates and the gradient estimates (for the days where the gradient estimates were robust) may be considered as surprising considering that the 
FIDES approach is based simply on the difference between mean ammonia concentrations at $1 \mathrm{~m}$, and hourly mean background values, while the gradient and REA estimates were the means of up to 4 replicated flux measurement systems. This indicates a high potential for future use of the FIDES approach as a low-cost approach to measure ammonia emission fluxes, so long as background concentrations are available.

This comparison can help the interpretation of $F_{m g}$ and $F_{a g}$ for the 4 days of high uncertainty in the AGM estimates (Fig. 4). On 8 June, the REA and FIDES estimates support $F_{a g}$, while on 9 June they support $F_{m g}$ as the best estimates. For 3 and 10 June the REA and FIDES support a flux midway between $F_{m g}$ and $F_{a g}$. The comparison is useful in considering uncertainties in relation to modelling (e.g., Personne et al., 2009), but further highlights the temporally variable performance of the individual $\mathrm{NH}_{3}$ fluxmeasurement systems through the experiment. With these caveats, overall the AGM is considered the most robust individual estimate, particularly for small fluxes before the cut, where the REA is less sensitive and the FIDES approach may be sensitive to other influences on the measured background values.

\subsection{Bioassay measurements to support the interpretation of ammonia fluxes}

The detailed series of results from the bioassays are reported by Mattsson et al. (2009a, b) and Herrmann et al. (2009). For the period before the cut, it was expected that the net exchange of ammonia would be controlled by the interaction of a stomatal compensation point concentration $\left(\chi_{s}\right)$ in equilibrium with the plant intercellular (apoplastic) aqueous solution with adsorption and desorption processes on the leaf surface (e.g., Schjoerring et al., 1998; Sutton et al., 1998a; Flechard et al., 1999).

With this rationale, there was a strong interest to measure apoplastic ammonium concentrations and $\mathrm{pH}$, as a basis to estimate the temperature-normalized compensation point parameter $\Gamma_{s} \quad\left(=\left[\mathrm{NH}_{4}^{+}\right]_{\text {apoplast }} /\left[\mathrm{H}^{+}\right]_{\text {apoplast }}\right.$, Sutton et al., 2000; Nemitz et al., 2001b). $\Gamma_{s}$ has the advantage over $\chi_{s}$ in that (excluding other physiological interactions) it is independent of temperature. For a given value of $\Gamma_{s}, \chi_{s}$, roughly doubles every $5{ }^{\circ} \mathrm{C}$ (Sutton et al., 2001a). Further parameters studied were bulk leaf tissue $\left[\mathrm{NH}_{4}^{+}\right]$, as an easierto-measure indicator of apoplastic $\left[\mathrm{NH}_{4}^{+}\right]$, and total soluble $\mathrm{N}$, a bioassay which was developed specifically for the experiment as an estimate of plant substrate $\mathrm{N}$ concentration (Sutton et al., 2009a).

Based on bioassay measurements prior to the cut, Mattsson et al. (2009b) demonstrated a substantial speciesdependence of estimated $\Gamma_{s}$ values. For example, they found a significant species correlation between mean $\Gamma_{s}$ and bulk foliar $\left[\mathrm{NH}_{4}^{+}\right]$, illustrating the potential of the latter as a simpler indicator of $\Gamma_{s}$. Their results suggest that the largest ammonia emission potential would occur for Festuca pratensis and Dactylus glomerata, with the lowest for Phleum pretense, Holcus lanatus and Bromus mollis. Thus the former plant species might emit ammonia that is simultaneously re-absorbed by the latter species. One caveat for this simpler indicator is there was only a modest temporal correlation between $\Gamma_{s}$ and bulk foliar $\left[\mathrm{NH}_{4}^{+}\right]$(Herrmann et al., 2009).

Based on earlier analyses (Sutton et al., 2001a; Loubet et al., 2002; Riedo et al., 2002), cutting of the grass sward was understood to cause an increase in foliar ammonium concentrations at least partly because of a cutting-induced reduction in photosynthetic, which would limit the carbon sink that otherwise consumes ammonium and other forms of substrate nitrogen to form proteins and other nitrogen compounds. With a reduced removal rate of ammonium from plant tissues, apoplastic ammonium concentrations would thus be expected to increase. Similarly, a further increase in foliar $\mathrm{N}$ indicators would be expected following nitrogen fertilization, with both these factors causing an increase in stomatal emissions of ammonia (Loubet et al., 2002; Riedo et al., 2002).

Mattsson et al. (2009a) report the detailed time course of the $\mathrm{N}$ indicators, apoplastic $\mathrm{pH}$ and $\Gamma_{s}$ through the Braunschweig Experiment. They also compared the responses of these indicators in the additional grassland management treatments applied to the Braunschweig field site. In addition to a treatment without fertilizer application, these management plots included a high $\mathrm{N}$ application rate treatment (Sutton et al., 2009a). Mattsson et al. (2009a) report little difference in the values of the bioassays (apoplastic $\mathrm{N}$, apoplastic $\mathrm{pH}$, soluble and total $\mathrm{N}$ ) between the normal $\mathrm{N}$ treatment and high $\mathrm{N}$ treatment. Given a relatively high degree of scatter in these measurements, we therefore summarize the results here combining the data for these two treatments to allow the temporal trends to be seen more clearly (Fig. 6). For the purpose of this comparison, we have combined the available datasets from Mattsson et al. (2009a, b) and Herrman et al. (2009).

The simplest measurement shown in Fig. 6 is the total foliar nitrogen concentration ( $\%$ dry weight). A decline is seen before the cut, linked to growth-dilution in the grass, which continues in the uncut-unfertilized plot. Total foliar $\mathrm{N}$ concentration increased after both cutting and fertilization. Part of this trend can be related to $\mathrm{N}$ remobilization and uptake following cutting and fertilization. However, it should be noted that the measurements after cutting were made on young re-growing leaves, rather than on mature leaves before the cut.

The newly tested parameter, "substrate N" (total soluble $\mathrm{N})$ showed a broadly similar decline to total $\% \mathrm{~N}$ for the uncut-unfertilized plot. Maximum values were recorded after cutting, which then declined steeply, although this decline was less where the field was fertilized. If this parameter had been controlling ammonia emissions from the foliage, 

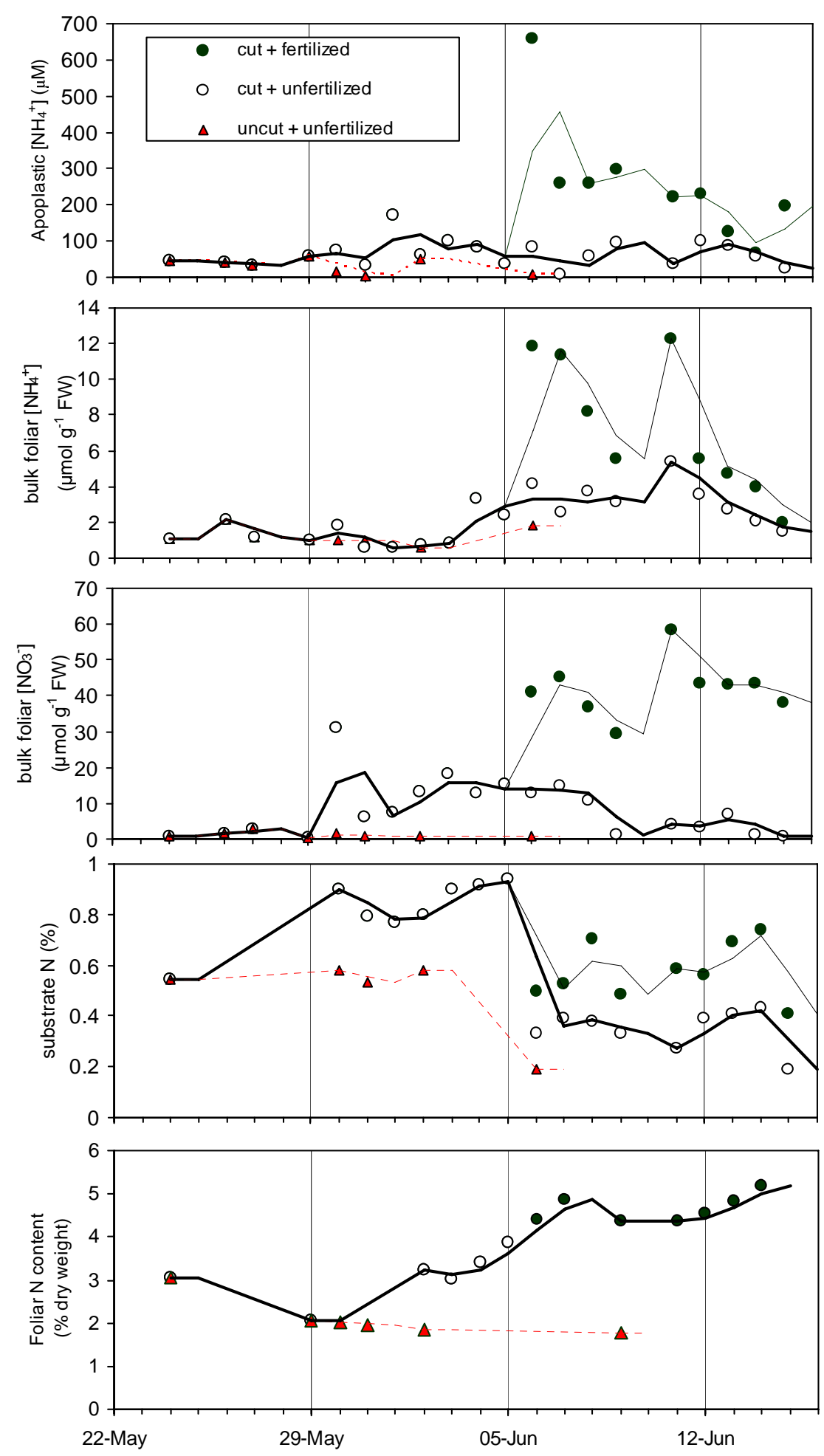

Fig. 6. Daily course of apoplastic $\left[\mathrm{NH}_{4}^{+}\right]$, total foliar $\left[\mathrm{NH}_{4}^{+}\right]$, total foliar $\left[\mathrm{NO}_{3}^{-}\right]$and total soluble N. Full details, with apoplastic $\left[\mathrm{H}^{+}\right]$and $\chi_{s}$ and standard errors are reported by Mattsson et al. (2009a). The field was cut on 29 May and fertilized on 5 June. Results shown for these days represent conditions prior to these changes. The values for "fertilized" here represent the mean of results from the main field and the high $\mathrm{N}$ treatment (plots B1 and B3 described by Sutton et al., 2009a). The lines are 2-point running means. 


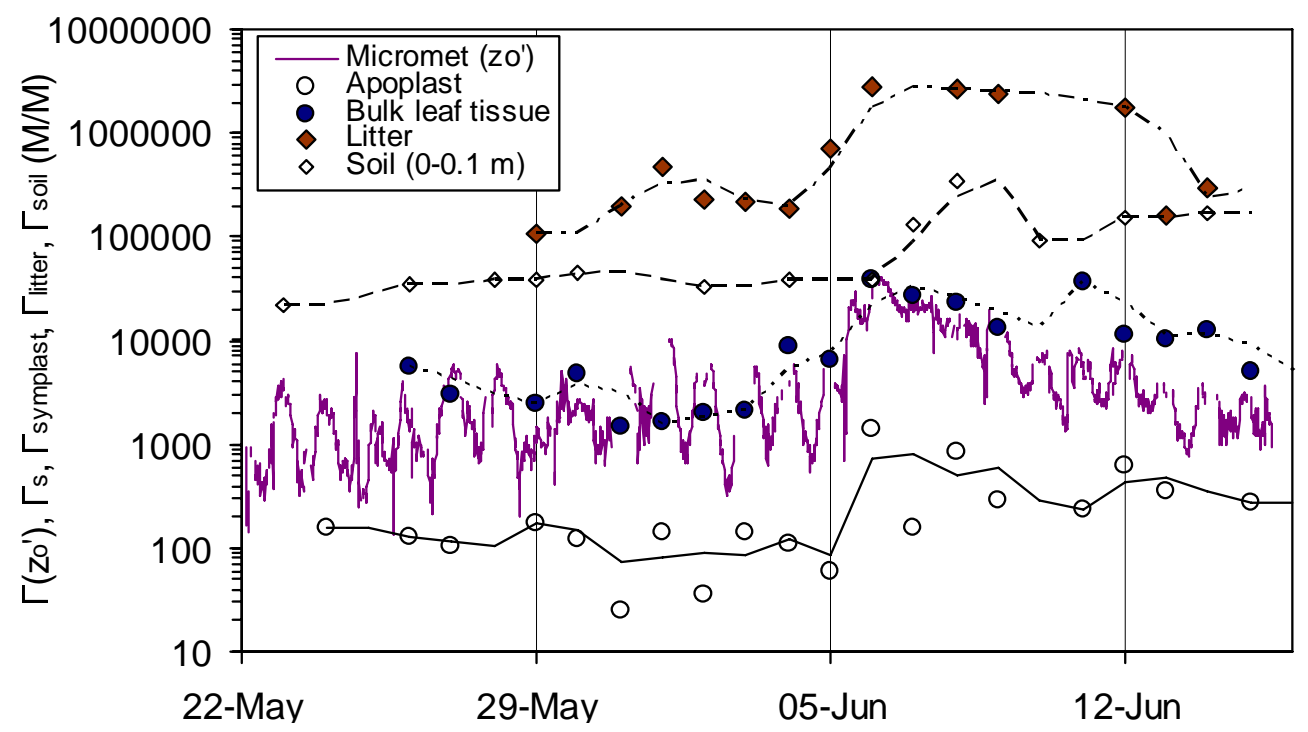

Fig. 7. Time course of estimated $\Gamma$ values (ratio of $\left[\mathrm{NH}_{4}^{+}\right] /\left[\mathrm{H}^{+}\right]$) in different compartments throughout the GRAMINAE experiment. Values refer to the main field. Values of $\Gamma$ for bulk leaf tissue and litter are shown here for dry matter contents of $10 \%$ and $40 \%$, respectively. The semi-continuous record of $\Gamma\left(z_{o}^{\prime}\right)$ is derived from micrometeorological estimation of the surface concentration, $\chi\left(z_{o}^{\prime}\right)$ and solubility equilibria using the surface temperature, $T\left(z_{o}{ }^{\prime}\right)$.

the largest emissions would have been expected immediately after the cut.

For completeness, bulk foliar analyses were made for both $\left[\mathrm{NH}_{4}^{+}\right]$and $\left[\mathrm{NO}_{3}^{-}\right]$. The purpose of measuring $\left[\mathrm{NO}_{3}^{-}\right]$was to see any foliar responses to altered nitrate availability. Uniformly low values of both parameters were found for the uncut-unfertilized treatment. By contrast, while $\left[\mathrm{NO}_{3}^{-}\right]$ increased after cutting, no increase was observed in $\left[\mathrm{NH}_{4}^{+}\right]$. Similarly, hardly any increase was detected in apoplastic $\left[\mathrm{NH}_{4}^{+}\right]$following cutting. These observations suggest that the increase in ammonia emission following cutting is not related to an increase in the foliar $\left[\mathrm{NH}_{4}^{+}\right]$emission potential. In the case of bulk foliar $\left[\mathrm{NO}_{3}^{-}\right]$, the larger values after cutting may be related to young leaves being sampled, while soil $\left[\mathrm{NO}_{3}^{-}\right]$values remained low during this period (Sutton et al., 2009a). Larger values of bulk $\left[\mathrm{NO}_{3}^{-}\right],\left[\mathrm{NH}_{4}^{+}\right]$and apoplastic $\left[\mathrm{NH}_{4}^{+}\right]$were recorded after fertilization, indicating fertilizer $\mathrm{N}$ uptake by the plant, which had not yet been incorporated into organic $\mathrm{N}$ compounds.

There has been a long-standing discussion on a possible bias in $\Gamma_{s}$ estimates based on apoplastic extraction (Husted et al., 2000a; Hill et al., 2001; Loubet et al., 2002; van Hove et al., 2002). For example, comparison with gas exchange estimates has sometimes suggested that the bioassay approach may underestimate $\Gamma_{s}$ (Hill et al., 2001; Mattsson and Schjoerring, 2002). Potential reasons include inter-cellular spatial variability in $\left[\mathrm{NH}_{4}^{+}\right]$and $\left[\mathrm{H}^{+}\right]$, as well as uncertainty in the leaf extraction corrections for $\left[\mathrm{NH}_{4}^{+}\right]$ and $\left[\mathrm{H}^{+}\right]$(Mattsson et al., 2009a, b).
Averaging between species may also affect the $\Gamma_{s}$ values estimated. For example, if $\Gamma_{s}$ is calculated for each grass species in Fig. 6, the unweighted species mean is 246. By contrast, if the mean $\mathrm{pH}$ and the mean $\left[\mathrm{NH}_{4}^{\mathrm{r}}\right]$ for all species are calculated, the $\Gamma_{s}$ value derived from the ratio of means would be 153 . (The same calculation using mean $\left[\mathrm{NH}_{4}^{+}\right]$ and mean $\left[\mathrm{H}^{+}\right]$gives $\left.\Gamma_{s}=117\right)$. This example illustrates the potential for natural variability so that a few high $\Gamma_{s}$ leaves could dominate the net emission. Overall, the potential underestimation of $\Gamma_{s}$ by the bioassay method may be up to a factor of 2 to 4 , though other non-stomatal sources may also account for such differences, as discussed by Hill et al. (2001).

Diurnal variability in $\Gamma_{s}$ may also be expected, given the intra-cellular production of ammonia during photorespiration (Husted et al., 2002). Herrmann et al. (2009) found little diurnal variation for the Braunschweig grassland, consistent with Husted et al. (2000b) for oilseed rape. By contrast, the same authors showed strong vertical profiles of $\Gamma$, with much larger values of $\Gamma$ for brown than for green leaves. Mineralization of organic nitrogen compounds in decaying leaf litter has the potential to increase $\mathrm{NH}_{3}$ emission substantially compared with live leaves (Whitehead et al., 1988; Nemitz et al., 2000a, b; Mattsson and Schjoerring, 2003). Herrmann et al. (2009) also showed that $\mathrm{NH}_{3}$ concentrations within the canopy air-space were larger than could be explained by the bioassay $\Gamma_{S}$ values. This suggests that, before the cut, the green leaves would have been a sink of ammonia emitted from underlying leaf litter.

While uncertainties remain in the absolute values of the bioassay $\Gamma_{s}$ values, it is useful to construct a series of 
different $\Gamma$ estimates from the Braunschweig Experiment (Fig. 7). In this figure, we combine estimates of $\Gamma_{s}$ from the apoplastic extraction, with $\Gamma_{\text {bulkleaftissue }}, \Gamma_{\text {leaf litter and }}$ $\Gamma_{\text {soil }(0-0.1 \mathrm{~m})}$, based on measured $\left[\mathrm{NH}_{4}^{+}\right], \mathrm{pH}$ and water content.

Figure 7 also shows calculated values of $\Gamma z_{o}{ }^{\prime}$ ), based on the micrometeorological flux measurements. This parameter was derived from $\chi\left(z_{o}{ }^{\prime}\right)$, which is the ammonia concentration extrapolated to the canopy surface accounting for the turbulent and quasi-laminar resistances for transport (Sutton et al., 1993). $\chi\left(z_{o}^{\prime}\right)$ was calculated for the timecourse of the Braunschweig Experiment based on $\chi_{m g}(1 \mathrm{~m})$ and $\left.F_{m g} . \quad \Gamma z_{o}^{\prime}\right)$ is calculated here from $\chi\left(z_{o}^{\prime}\right)$ using the values of canopy temperature, $T\left(z_{o}{ }^{\prime}\right)$, as reported by Sutton et al. (2009a). Under conditions of deposition, Го $z_{o}{ }^{\prime}$ ) represents an upper estimate of the actual canopy average $\Gamma$ (since additional surface resistances would reduce its value), while under conditions of emission, $\Gamma о z_{o}{ }^{\prime}$ ) represents a minimum estimate of the actual canopy average $\Gamma$.

Figure 7 reveals a startling picture of $\Gamma$ values varying over 5 orders of magnitude, from 30 to 3 million. The smallest values occur for $\Gamma_{s}$ with the largest for $\Gamma_{\text {litter. It should be }}$ emphasized that while $\Gamma_{s}$ values may be actively regulated by the plant, $\Gamma_{\text {litter }}$ is expected to fluctuate substantially in response to decomposition processes, availability of surface moisture and loss of $\mathrm{NH}_{3}$ to the atmosphere. The estimates of $\Gamma_{\text {litter }}$ shown reflect the temporal dynamics of $\left[\mathrm{NH}_{4}^{+}\right]_{\text {litter }}$, but not $\left[\mathrm{H}^{+}\right]_{\text {litter}}$, which was only measured on 29 June. Given these uncertainties, the $\Gamma_{\text {litter }}$ values shown here should be considered as indicative of the potential for ammonia emission, and do not necessarily imply that such emissions could be continuously sustained.

Comparison of the plant and soil $\Gamma$ values with $\Gamma \mathrm{o} z_{o}{ }^{\prime}$ ) shows the potential for these sources to explain the actual net ammonia fluxes observed during the experiment. By contrast, the measured $\Gamma_{s}$ values are consistently an order of magnitude smaller than $\Gamma z_{o}{ }^{\prime}$ ). While recognizing the uncertainties in the $\Gamma_{s}$ bioassay, it seems highly unlikely that the foliar apoplast was a key source of the ammonia emissions observed.

The values of $\Gamma_{\text {bulkleaf }}$ are illustrated under the hypothesis that, under certain circumstances, there could be other routes for ammonia loss from leaves. For example, wounding of the leaves directly after cutting could lead to short term emissions linked to $\Gamma_{\text {bulkleaf. These values are in some cases }}$ slightly larger than $\Gamma\left(z_{o}^{\prime}\right)$, though the comparison with $\Gamma_{\text {soil }}$ and $\Gamma_{\text {litter }}$ suggests that such wounding is a less likely source of ammonia emission, especially given the expected brief duration of any wounding effects.

The largest potential sources of ammonia emission are thus the soil and leaf litter. Prior to cutting on 29 May, the values of $\Gamma_{\text {soil }}$ and $\Gamma_{\text {litter }}$ were similar, and this position was eventually regained as the grass matured at the end of the experiment (14-15 June). Thus toward the end of the experiment soil and litter surface might have contributed similarly to potential ammonia emissions, though with the much larger pool-size of the soil, the actual contribution of $\Gamma_{\text {soil }}$ could have been larger. After cutting, $\Gamma_{\text {litter }}$ is much larger than $\Gamma_{\text {soil }}$, indicating this as the main source of emission from the cut grass. $\Gamma_{\text {litter }}$ increases again after fertilization, and remains larger than $\Gamma_{\text {soil }}$. After fertilization, pellets of ammonium nitrate were surely a major source, and it is likely that the larger $\Gamma_{\text {litter }}$ values for this period reflect the presence of adsorbed fertilizer ammonium.

These observations provide the basis for an alternative explanation of ammonia emissions following cutting of the Braunschweig grass than that discussed by Riedo et al. (2002) for a grassland site in Scotland. At Braunschweig, removal of the tall grass allowed ammonia emissions from the litter to reach the atmosphere, rather than being reabsorbed by the overlaying canopy (c.f. Denmead et al., 1976; Nemitz et al., 2000a, b). The overall increase in canopy temperature after cutting (Sect. 3.1) would have further increased the emissions from the cut field during the Braunschweig experiment (as discussed in Sect. 4.2 in relation to the SURFATM-NH $\mathrm{N}_{3}$ model). After fertilization, increased values of $\chi_{\text {litter }}$ and $\chi_{\text {soil }}$ would have further promoted emission. By contrast, there is no evidence from the data shown in Figs. 6 and 7 that cutting or fertilization led to apoplastic-mediated stomatal ammonia emissions at this site, though the increase in $\Gamma_{s}$ would have slightly reduced foliar recapture of ammonia emission after fertilization.

\subsection{Cuvette and within-canopy measurements}

Cuvette measurements and within-canopy ammonia concentration profiles provided further evidence understand the sources and sinks of ammonia in the Braunschweig canopy.

David et al. (2009a) used a cuvette system to measure ammonia fluxes during the field experiment and subsequently in the laboratory to investigate the main sources and sinks of ammonia. For the Braunschweig field, they found that removing all the vegetation from the cut sward (to leave bare soil) increased the rates of ammonia emission, indicating that there was some ammonia recapture to the short grass. Covering the bare soil surface with dry dead leaves reduced the rate of emission (a sheltering effect), while wetting this litter then increased the ammonia emission rate. This highlights the effect of moisture in allowing mineralization, and hence ammonia volatilization, as well as the role of the litter and soil surface for ammonia emission. By contrast, the presence of drying hay only slightly increased emissions compared with short grass with hay removed. David et al. (2009a) found a high correlation between $\mathrm{NH}_{3}$ emissions found with the cuvette system and the bioassay estimates of the different the compensation points based on actual surface temperatures and $\Gamma$ values $\left(\Gamma_{s}, \Gamma_{\text {bulkleaf }}, \Gamma_{\text {litter }}, \Gamma_{\text {soil }}\right.$ with calculated surface concentrations in the range $0.1-1060 \mu \mathrm{g} \mathrm{m}^{-3}$. 


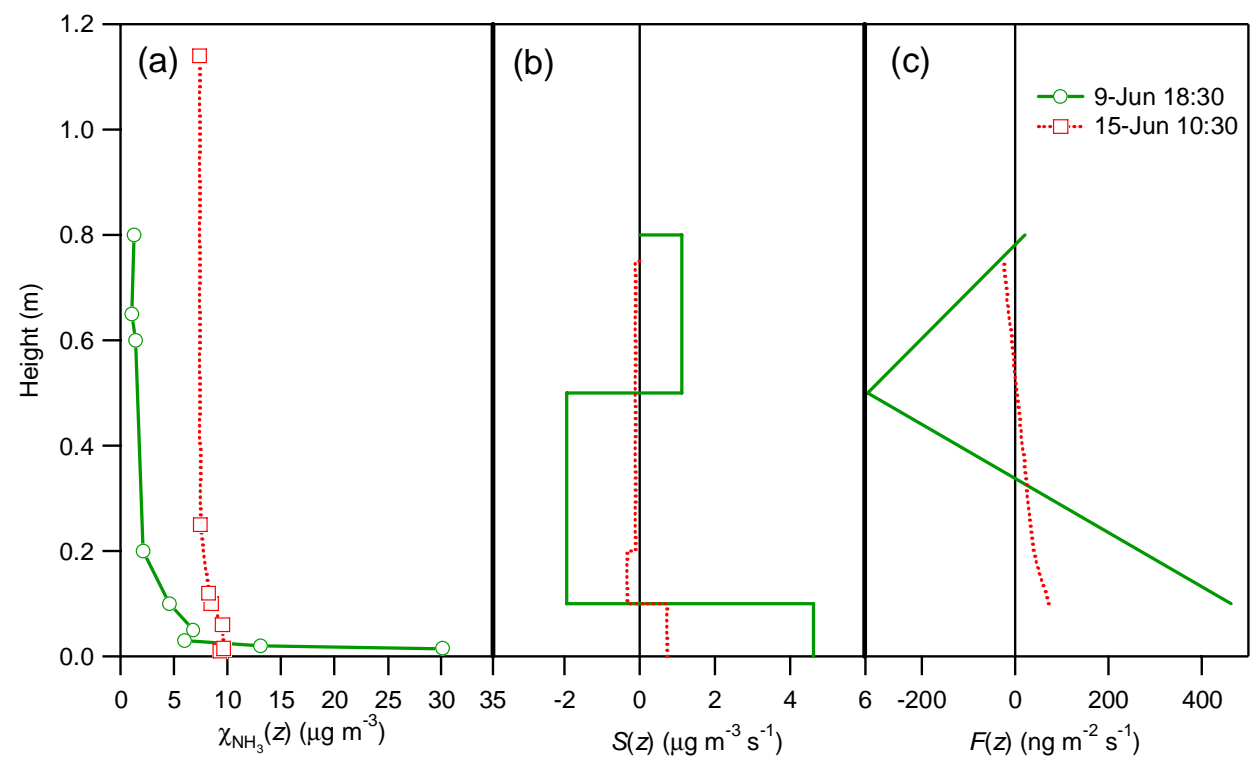

Fig. 8. Example application of the inverse Lagrangian technique based on near-field theory to derive the vertical ammonia source/sink profile in the grassland canopy during the GRAMINAE Integrated Experiment. (a) Ammonia concentration profiles for 9 June 18:30 and 15 June 10:30; (b) the ammonia source/sink density $(S(z))$ for defined layers within the canopy; (c) the estimated ammonia flux $(F(z))$ at the top of each layer.

David et al. (2009a, b) considered the effects of the management interactions on ammonia fluxes. Under zero ammonia concentration, they recorded a small ammonia emission 0.1 to $3.3 \mathrm{ng} \mathrm{m}^{-2} \mathrm{~s}^{-1}$ for the long grass sward (pre-cut). They estimated that in the presence of ambient ammonia at $3 \mu \mathrm{g} \mathrm{m}^{-3}$ a net deposition flux would have been recorded, consistent with the pattern of small bidirectional fluxes reported by Milford et al. (2009). After the sward was cut, ammonia emissions were much larger (3 to $30 \mathrm{ng} \mathrm{m}^{-2} \mathrm{~s}^{-1}$ ), which David et al. (2009b) explain as being only partly related to warmer conditions for the later period. These represent much smaller absolute values of the flux than recorded in the micrometeorological measurements, which was explained by much lower turbulence within the cuvettes.

Following cutting, leaf litter is no longer protected from atmospheric turbulence by the overlaying canopy, while the cutting process itself also induces leaf senescence. These changes are coupled with a larger fraction of incoming solar radiation being transformed into sensible heat, due to the smaller amount of green leaves (Cellier et al., 1996), which further increases surface temperature and decreases relative humidity. In terms of diurnal changes, these effects would have led to more rapid fluctuations of surface temperature and moisture conditions following the cut. By contrast, during night, the litter would be directly exposed to dewfall, increasing mineralization and providing a larger $\mathrm{NH}_{4}^{+}$ reservoir for subsequent ammonia emissions (David et al., 2009a, b).

Based on these factors, the larger net ammonia emissions observed after cutting should be a response to both a) reduced recapture of litter $\mathrm{NH}_{3}$ emissions by the short grass canopy and $b$ ) the fact that the litter emissions were larger due to increased turbulence at the ground, warmer conditions and more diurnally fluctuating temperature and moisture.

Nemitz et al. (2009c) examined the within-canopy transport processes for the tall grass during the Braunschweig experiment. They applied a micro-ultrasonic anemometer and hot-wire anemometers to measure within-canopy turbulence in the mid and upper part of the canopy. These methods could only be applied down to about 0.1 of $z / h_{\text {canopy }}$, leaving uncertainty very close to the ground. The authors also applied a radon tracer method based on the decay rate of ${ }^{220} \mathrm{Rn}$, which is naturally emitted by soils (Lehman et al., 1999). Nemitz et al. (2009c) demonstrated a very low rate of turbulent mixing within the tall grass sward $(0.7-0.8 \mathrm{~m})$, with the ratio of turbulence within the canopy to that above the canopy decreasing to around 0.1 at $0.07 \mathrm{~m}$ above the ground $\left(\sigma_{w} / u_{*}\right.$ where $w$ is the instantaneous vertical wind speed). Near-ground eddy diffusivities derived with the ${ }^{220} \mathrm{Rn}$ tracer method were very small and are only consistent with the measurements of $\sigma_{w} / u_{*}$ if the magnitude of the Lagrangian timescale (which could not be measured directly during the study) is at the bottom end of the range of parametrizations proposed in the literature.

While the analysis of Nemitz et al. (2009c) provides fundamental advances in quantifying within-canopy turbulence processes, due to a failure of one channel in the mini-WEDD system before the cut, it was only possible to obtain a few $\mathrm{NH}_{3}$ concentration profile measurements profiles within the canopy. Figure 8 illustrates example 
profiles obtained on 9 and 15 June using a fast response ammonia detector (Hensen et al., 2009a), applied in an un-cut part of the field after the main field was cut (see Fig. 5 in Sutton et al., 2009a). This instrument provided relative $\mathrm{NH}_{3}$ concentrations which were referenced against $\chi_{m g}(1 \mathrm{~m})$ of Milford et al. (2009), though for the dates shown this correction was only $\sim 10 \%$. Although the detailed source-sink profile remains uncertain, the inverse Lagrangian analysis of Nemitz et al. (2009c) summarized in Fig. 8, qualitatively confirms the ground $\mathrm{NH}_{3}$ source with recapture by the overlaying canopy. The larger ground $\mathrm{NH}_{3}$ emissions recorded on 15 June 10:45 may be partly due to drying conditions at this time occurring after a moist night with light rain, which would have favoured mineralization of leaf litter.

\subsection{Surface-atmosphere exchange of other trace gas and aerosol}

Concentrations and fluxes of other gases measured during the GRAMINAE experiment included ozone $\left(\mathrm{O}_{3}\right)$ and $\mathrm{CO}_{2}$ (Meszaros et al., 2008) sulphur dioxide $\left(\mathrm{SO}_{2}\right)$, nitric acid $\left(\mathrm{HNO}_{3}\right)$ and particulate matter (Sutton et al., 2009a; Nemitz et al., 2009a). Inferential modelling of $\mathrm{O}_{3}$ deposition using measured concentrations showed close agreement to the measured fluxes (overall within $20 \%$ for the pre-cut period and within $10 \%$ for the pre-fertilizer period and after fertilization). Based on the model analysis, the fraction of $\mathrm{O}_{3}$ deposition taken up by stomata was $0.57,0.33$ and 0.29 , for the three successive management periods, demonstrating the importance of $\mathrm{O}_{3}$ uptake to leaf and soil surfaces. The cut lowered the $\mathrm{O}_{3}$ deposition flux less than would be expected on the basis of the change in leaf area. The model demonstrates that the reduction in deposition to the foliage is partially balanced by increased deposition to the more accessible soil surface, although non-stomatal deposition also seems more effective (per leaf area) after the cut, either due to increased temperatures or chemical destruction by NO or VOCs stimulated after cut and fertilization.

Prior to cutting, the field was a significant $\mathrm{CO}_{2}$ sink (accumulating $300 \mathrm{~kg} \mathrm{Cha}^{-1}$ during 20-29 May), changing to a net $\mathrm{CO}_{2}$ source after cutting (loss of $150 \mathrm{~kg} \mathrm{Cha}^{-1}$ during 29 May to 7 June, data not shown). Only after 11 June did net $\mathrm{CO}_{2}$ uptake resume, coinciding with a return to cooler conditions with smaller $\mathrm{NH}_{3}$ emissions (daily maxima $<300 \mathrm{ng} \mathrm{m}^{-2} \mathrm{~s}^{-1}$ ).

Gradients of reactive inorganic gases and aerosol components were measured with a forerunner of the GRAEGOR instrument (Thomas et al., 2009), coupling the wet denuder method with steam jet aerosol collectors (SJAC). Concentrations of $\mathrm{SO}_{2}$ were mostly $<3 \mu \mathrm{g} \mathrm{m}^{-3}$ and too small to detect fluxes using the GRAEGOR, with possible bi-directional fluxes estimated by the chemiluminescence detector (CLD) also being rather uncertain. The exception was a period of more polluted air with SSE flow, which had passed over high emission areas around Czech Republic, arriving at Braunschweig on 9-10 June, with $\mathrm{SO}_{2}$ concentrations $3-10 \mu \mathrm{g} \mathrm{m}^{-3}$ (Sutton et al., 2009a). For this period, the CLD showed consistent $\mathrm{SO}_{2}$ deposition.

The period of 9-10 June also showed the highest $\mathrm{HNO}_{3}$ concentrations $\left(1-8 \mu \mathrm{g} \mathrm{m}^{-3}\right)$. With these conditions, the GRAEGOR method showed meaningful concentration gradients, with bi-directional fluxes being reported by Nemitz et al. (2009a). During the period with highest $\mathrm{SO}_{2}$ and $\mathrm{HNO}_{3}$ concentrations, the deposition velocity $\left(V_{d}\right)$ for $\mathrm{HNO}_{3}$ was much less than that normally expected (i.e., $V_{d}$ was smaller than $V_{\max }$, the reciprocal of the combined turbulent and quasi-laminar resistance), with short periods of emission. This observation is consistent with a limitation of $\mathrm{HNO}_{3}$ deposition under warm dry conditions in the presence $\mathrm{NH}_{4} \mathrm{NO}_{3}$ on the ground and high concentrations of $\mathrm{NO}_{3}^{-}$in the soil solution (Nemitz et al., 2009a).

Vertical gradients in aerosol chemistry from the GRAEGOR proved too small to determine chemicallyspeciated aerosol fluxes. However, overall particle number fluxes were measured independently by eddy covariance using a Condensation Particle Counter (CPC), and were found to be intimately related to the ammonia fluxes (Nemitz et al., 2009a). The time-course of particle number fluxes measured by the CPC is shown in Fig. 9. Despite substantial scatter in the measured fluxes, bi-directional patterns are clearly shown. Overall, aerosol number fluxes before the cut are negative (deposition), with a mean of -180 $\# \mathrm{~cm}^{-2} \mathrm{~s}^{-1}$ (mean $V_{d}=0.24 \mathrm{~mm} \mathrm{~s}^{-1}$ ). Following the cut,

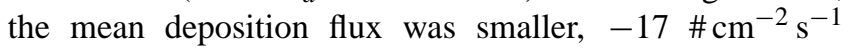
(mean $V_{d}=0.03 \mathrm{~mm} \mathrm{~s}^{-1}$ ) after peaks in particle emission associated with agricultural management had been removed (cutting of the grass on 29 May, turning of the cut-grass to dry it on 30 May, and removal of the cut-grass, for use as silage, on 31 May; these peaks are visible in Fig. 9). For the week after the grass was fertilized 5-11 June, the mean particle flux was positive $320 \mathrm{\#} \mathrm{cm}^{-2} \mathrm{~s}^{-1}$ indicating apparent particle emissions from the canopy. Finally, for 12-15 June, the mean particle flux was toward deposition at $-60 \# \mathrm{~cm}^{-2} \mathrm{~s}^{-1}$ (mean $V_{d}=0.06 \mathrm{~mm} \mathrm{~s}^{-1}$ ).

While the peaks in particle emissions associated with mechanical farm operations are expected, the apparent sustained particle emissions following the application of mineral nitrogen fertilizer represent a new observation. The fact that these 'emissions' correlate closely to the periods of maximum ammonia emission (especially on 6 to 9 June), clearly links them to the ammonia exchange process. In a detailed analysis of this observation, Nemitz et al. (2009a) show that it can be explained by particle growth induced by $\mathrm{NH}_{3}$ emissions from the field surface. The CPC detects particles in the diameter $\left(D_{p}\right)$ range $11 \mathrm{~nm}<D_{p}<3 \mu \mathrm{m}$. Immediately above the soil and litter surface, large concentrations of ammonia, $\left(\chi\left(z_{o}{ }^{\prime}\right)\right.$ up to $150 \mu \mathrm{g} \mathrm{m}^{-3}$, Nemitz et al., 2009a), combined with ambient 


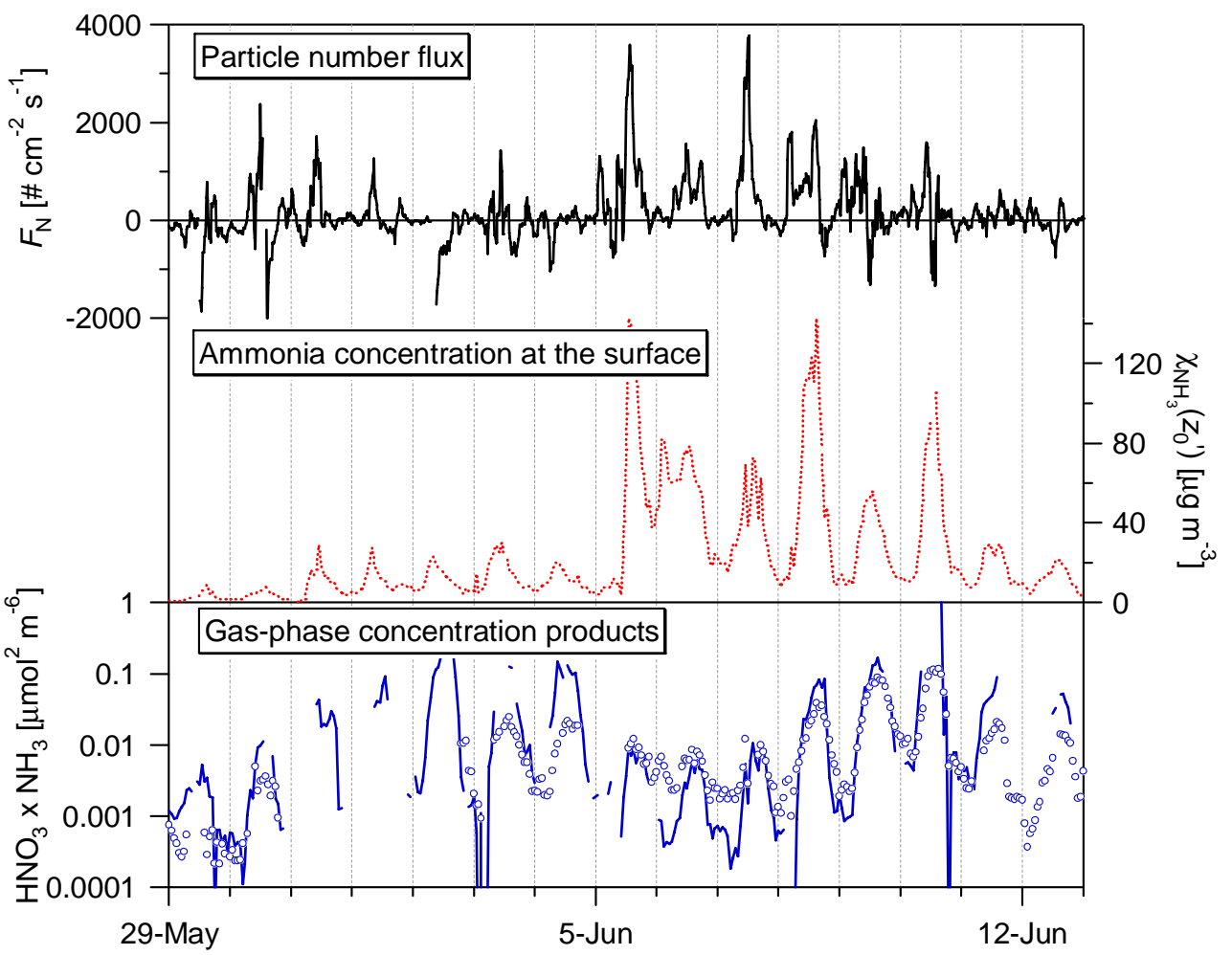

Fig. 9. Particle interactions during the GRAMINAE Integrated Experiment. Top: Time-series of particle fluxes ( $11 \mathrm{~nm}$ to $2 \mu \mathrm{m})$ in relation to grassland management. The grass was cut, turned and lifted on the mornings of 29, 30 and 31 May, respectively. Middle: Ammonia surface concentration $\chi\left(z_{o}^{\prime}\right)$, based on measured fluxes. Bottom: comparison of the measured product $\left[\mathrm{HNO}_{3}\right]\left[\mathrm{NH}_{3}\right]$ at $1 \mathrm{~m}$ (circles) compared with temperature- and humidity-dependent equilibrium values above-which particle formation is favoured.

$\mathrm{HNO}_{3}$ concentrations, exceed the equilibrium concentration product for formation of $\mathrm{NH}_{4} \mathrm{NO}_{3}$ in the aerosol phase. This effect leads to the condensation of additional $\mathrm{NH}_{4} \mathrm{NO}_{3}$ onto existing aerosol so that they grow above the $11 \mathrm{~nm}$ lower size limit detectable by the CPC during the deposition process. This results in a deposition gradient of total particle numbers, and a simultaneous apparent emission gradient of particle numbers $>11 \mathrm{~nm}$, which is detected by the CPC flux system. In principle, the reaction of $\mathrm{NH}_{3}$ with atmospheric $\mathrm{HCl}$ can also contribute to this process. Nemitz et al. (2009a) show that this was unlikely in this example, since the measured concentration product $\left[\mathrm{NH}_{3}\right][\mathrm{HCl}]$ did not exceed the equilibrium for formation of aerosol phase $\mathrm{NH}_{4} \mathrm{Cl}$.

It has been hypothesized in the past that litter and other emissions of $\mathrm{NH}_{3}$ could influence aerosol dynamics (e.g., Bigg, 2004). However, Nemitz et al. (2009a) demonstrate this phenomenon for the first time based on field-scale effects at the canopy-atmosphere interface $(0-2 \mathrm{~m})$. Nemitz et al. (2009a) present a new approach capable of quantifying particle growth rates from measurements at the field-scale, with potential for application beyond the $\mathrm{NH}_{3}-\mathrm{HNO}_{3}$ $\mathrm{NH}_{4} \mathrm{NO}_{3}$ system (e.g., to study biogenic secondary organic aerosol formation above vegetation). In classical studies, growth rates are calculated tracking aerosol size-modes as particles age over periods of hours and days (e.g., Kulmala et al., 2004). Using the new approach, Nemitz et al. (2009a) derive average particle diameter growth rates of 7.0 and $1.8 \mathrm{~nm} \mathrm{~h}^{-1}$ over the first 9 days following fertilization for $11 \mathrm{~nm}$ particles during day and night-time conditions, respectively.

Nemitz et al. (2009a) also address the consequences of this $\mathrm{NH}_{3}-\mathrm{HNO}_{3}-\mathrm{NH}_{4} \mathrm{NO}_{3}$ interaction for flux measurements of each of the components. As the process is mainly driven by large concentration profiles of $\mathrm{NH}_{3}$ (reflecting large fluxes), the relative divergence in $\mathrm{NH}_{3}$ fluxes is small, and effectively negligible compared with other sources of uncertainty (see Fig. 7 of Nemitz et al., 2009a). It implies a precision of better than $1 \%$ would have been needed for the REA systems to quantify such $\mathrm{NH}_{3}$ flux divergence directly. By contrast, given small $V_{d}$ of particles, there are significant effects on the estimation of particle deposition rates.

\section{Modelling of ammonia exchange dynamics}

Three different models were applied to investigate the temporal behaviour of measured ammonia fluxes and the contributing component fluxes. Each of the models 

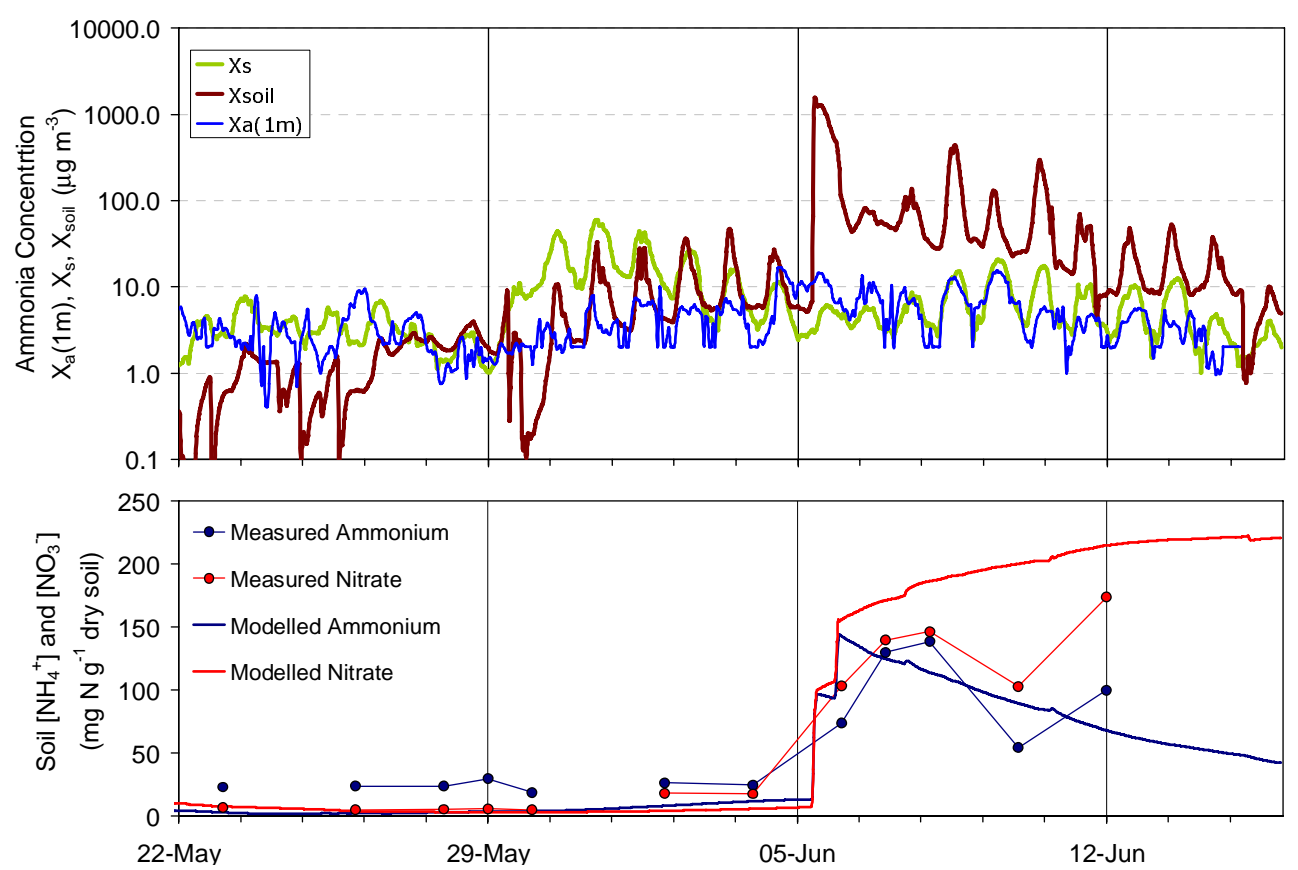

Fig. 10. Illustration of stomatal ammonia compensation point $\left(\chi_{s}\right)$ and soil surface ammonia concentration $\left(\chi_{\text {soil }}\right)$ estimated by a base simulation with the PaSim model for the Braunschweig Experiment. Measured top-soil ammonium and nitrate concentrations (0 to 0.1 m) are compared with the PaSim estimates. The simulated value of $\chi_{\text {soil }}$ applies to the surface layer of the soil (top $1 \mathrm{~mm}$ ), while $\chi_{s}$ is a bulk value for the overlaying canopy.

applied the concepts of bi-directional ammonia exchange and "canopy compensation points" in a resistance framework, as discussed by Sutton and Fowler (1993), Sutton et al. (1998a) and Nemitz et al. (2000b, 2001b). The following three models are applied:

Pasture Simulation (PaSim) model of Riedo et al. (2002). This provides a detailed treatment of grassland C$\mathrm{N}$ turnover processes including bi-directional $\mathrm{NH}_{3}$ exchange using the 2-layer approach of Nemitz et al. (2001b). The $\mathrm{NH}_{3}$ exchange part includes a stomatal compensation point $\left(\chi_{s}\right)$, deposition to leaf surfaces limited by a cuticular resistance $\left(R_{w}\right)$, and bi-directional exchange with a ground surface concentration $\left(\chi_{\text {soil }}\right)$. PaSim calculates $\chi_{s}$ directly based on $\mathrm{C}-\mathrm{N}$ turnover in the plant and partitioning of $\mathrm{N}$ between structural, substrate and apoplastic pools, while $\chi_{\text {soil }}$ is calculated using a multi-layer description of soil processes.

SURFATM-NH ${ }_{3}$ model, which is a new development described by Personne et al. (2009). This model provides a 2-layer treatment of the canopy which simulates latent and sensible heat fluxes and ammonia, by coupling an energy balance model (slightly modified from Choudhury and Monteith, 1988) with the 2-layer model of Nemitz et al. (2001b). The $\mathrm{NH}_{3}$ exchange scheme applies a cuticular deposition resistance $\left(R_{w}\right)$ with values of $\chi_{s}, \chi_{\text {soil }}$ and $\chi_{\text {litter }}$ calculated from modeled surface temperatures and empirical values of $\Gamma_{s}, \Gamma_{\text {soil }}, \Gamma_{\text {litter }}$, which must be provided as model inputs.
Dynamic cuticular chemistry model (DCC). A 1layer version is first used by Burkhardt et al. (2009) as an application of the model of Flechard et al. (1999), including empirical values of $\Gamma_{s}$ and bi-directional leaf surface exchange based on adsorption/desorption resistance and concentration terms $\left(R_{d}, \chi_{d}\right.$, Sutton et al., 1998a). In this model, $\chi_{d}$ and $\Gamma_{d}$ are calculated using simulated cuticular $\mathrm{pH}$ calculated by ion balance, including oxidation to $\mathrm{SO}_{4}^{2-}$, and the role of base cations (Flechard et al., 1999). Burkhardt et al. (2009) then extend the model to apply a new 2-layer formulation that also accounts for emissions from litter or the soil $\left(\Gamma_{g}\right)$.

The three models applied thus have different emphases. PaSim represents a complete grassland system driven by simple (but comprehensive) inputs focused on ecosystem functioning and $\mathrm{C}-\mathrm{N}$ turnover. SURFATM- $\mathrm{NH}_{3}$ represents a detailed soil vegetation atmosphere transfer (SVAT) scheme, based on empirical $\Gamma$ values, while the DCC model focuses on the role played by adsorption/desorption processes on leaf surfaces, particularly as these may be modified by different mixtures of acidic and basic gases. Lists of the model input parameters have been provided by Flechard et al. (1999), Riedo et al. (2002) and Personne et al. (2009).

\subsection{Application of the PaSim model}

The ammonia module of PaSim was developed based on the interpretation of flux and bioassay measurements made 
over an intensively managed permanent pasture in southern Scotland (Milford et al., 2001b; Riedo et al., 2002; Loubet et al., 2002). It was therefore of interest to see how the model performs for the Braunschweig grassland, which was sown 4 years prior to the experiment and has a more continental climate. The model was initialized to conditions on 1 January 2000 and run until 15 June 2000, using hourly meteorology from Site 7 for the period prior to the experiment (See map, Sutton et al., 2009a). Hourly mean $\mathrm{NH}_{3}$ and $\mathrm{CO}_{2}$ concentrations measured at Site $1(1 \mathrm{~m})$ were used as inputs during the experiment period, with fixed values of $2 \mu \mathrm{g} \mathrm{m}^{-3}$ and $365 \mathrm{ppm}$, respectively, applied for the earlier period. No changes were made to the model for the base simulation, so that the differences in output from Riedo et al. (2002) are entirely a function of the different soil, management and meteorological conditions. Sensitivity tests were made to help interpret the model results.

Example outputs from the PaSim base simulation of the Braunschweig experiment are shown in Figs. 10 and 11. The lower part of Fig. 10 shows that the model was able to capture the main variation in $\left[\mathrm{NH}_{4}^{+}\right]$and $\left[\mathrm{NO}_{3}^{-}\right]$ for the top soil $(0-0.1 \mathrm{~m})$. Although soil $\left[\mathrm{NH}_{4}^{+}\right]$was somewhat underestimated prior to fertilization, the increase and subsequent decrease (which was faster than for $\left[\mathrm{NO}_{3}^{-}\right]$) are clearly shown. In order to simulate $\mathrm{NH}_{3}$ transfers at the soil surface, PaSim includes a shallow surface layer $(1 \mathrm{~mm}$ depth) in which fertilizer dissolution takes place and with which $\mathrm{NH}_{3}$ exchanges. Following fertilization, $\left[\mathrm{NH}_{4}^{+}\right]$will be much larger in this layer than in the layer 0 to $0.1 \mathrm{~m}$ shown here.

The top part of Fig. 10 shows the stomatal compensation point $\left(\chi_{s}\right)$ and the soil surface $\mathrm{NH}_{3}$ concentration $\left(\chi_{\text {soil }}\right)$ compared with $\chi(1 \mathrm{~m})$. The relative size of these concentrations indicates the potential for emission and deposition, with actual fluxes constrained by the different component resistances. Before the cut, modelled $\chi_{s}$ is similar in magnitude to $\chi_{a}$, implying small bi-directional stomatal fluxes, while modelled $\chi_{\text {soil }}$ is mostly smaller. After the cut, both modeled $\chi_{s}$ and $\chi_{\text {soil }}$ increase substantially implying larger emissions. Finally, after fertilization, modelled $\chi_{\text {soil }}$ increases greatly (to $1000 \mu \mathrm{g} \mathrm{m}^{-3}$ ), so that soil emissions would dominate net fluxes.

The fluxes simulated by PaSim are compared with measured net fluxes in Fig. 11, together with the simulated component soil, stomatal and cuticular fluxes. Overall, PaSim is able to reproduce net fluxes for the three main management periods, as well as the diurnal variability. This level of agreement is very encouraging, given that the model was applied based on a parametrization developed for Scottish conditions. The main differences from the measurements are: a) an overestimation of diurnal variation before the cut, b) underestimation of emissions after the cut and c) underestimation of emissions for days 2-3 after fertilization. The last difference is easily explained: PaSim assumes an empirical fertilizer dissolution rate, after which $\left[\mathrm{NH}_{4}^{+}\right]$is available for emission from the soil surface. The model sensitivity tests (not shown) suggested that this simplistic treatment led to over-rapid dissolution of the fertilizer into the top soil layer, as compared with observed fluxes.

While PaSim is able to distinguish the changes in measured net $\mathrm{NH}_{3}$ fluxes, its weakness concerns estimation of the component fluxes. PaSim estimates much larger $\chi_{s}$ than is justified by the bioassay measurements, with a strong increase in $\chi_{s}$ and stomatal emissions after cutting. The partitioning is better following fertilization, with simulated ground emissions dominating net fluxes, but here it must be noted that PaSim does not describe leaf litter dynamics or emissions. Thus after cutting, the overestimates of $\chi_{s}$, combined with increased values of $\chi_{\text {soil }}$, tend to compensate for the absence of litter $\mathrm{NH}_{3}$ emissions in the model.

\subsection{Application of the SURFATM-NH $\mathrm{NH}_{3}$ model}

The development and application of SURFATM- $\mathrm{NH}_{3}$ is described in detail by Personne et al. (2009). The formulation of $R_{w}$ is the same as that used by in PaSim, following Milford et al. (2001b) and Sutton et al. (2001), with $R_{w}=a \exp ^{([100-\mathrm{RH}] / b)}$, where $a=30 \mathrm{~s} \mathrm{~m}^{-1}$ and $b=7$ and $\mathrm{RH}$ is $\%$ relative humidity at $1 \mathrm{~m}$. The procedures for estimating the atmospheric turbulent, boundary layer and soil surface resistances are, however, independent. SURFATM$\mathrm{NH}_{3}$ requires input data of $\mathrm{NH}_{3}$ concentration at a reference height $\left(\chi_{m g}(1 \mathrm{~m})\right.$ was used). The meteorological inputs are air temperature, relative humidity, net radiation, windspeed and precipitation, for which the consensus estimates were used (Nemitz et al., 2009b). Other inputs include soil water content, leaf area index and canopy height.

In contrast to PaSim, SURFATM-NH $\mathrm{N}_{3}$ does not simulate $\Gamma_{s}$, but was run using interpolated estimates from the bioassays (cf. Fig. 7). In a first scenario, the ground surface emission potential was based on the measured estimates of $\Gamma_{\text {soil }}$, under the hypothesis that emitted $\mathrm{NH}_{3}$ comes from the boundary between wet and dry soil. For this purpose the soil temperature at this boundary was estimated $\left(T^{*}\right.$ soil $)$ with the soil transfer resistance $\left(R_{\text {soil }}\right)$. In a second scenario, the surface emission potential was hypothesized to be driven by the litter, with the values based on measured estimates of $\Gamma_{\text {litter }}$, combined with the soil surface temperature $\left(T_{s s}\right)$ and an empirical litter resistance assuming completely inactive stomata $\left(R_{\text {litter }}=5000 \mathrm{~s} \mathrm{~m}^{-1}\right)$.

Both scenarios were able to reproduce the main temporal features of the measured ammonia emissions. The soil emission scenario underestimated $\mathrm{NH}_{3}$ emissions by around $60 \%$ during the post-cut period, while the litter emission scenario overestimated emissions by around $30 \%$. In addition, the soil emission scenario was unable to reproduce the initial peak of ammonia emissions following fertilization. This is presumably linked to the uncertainty 

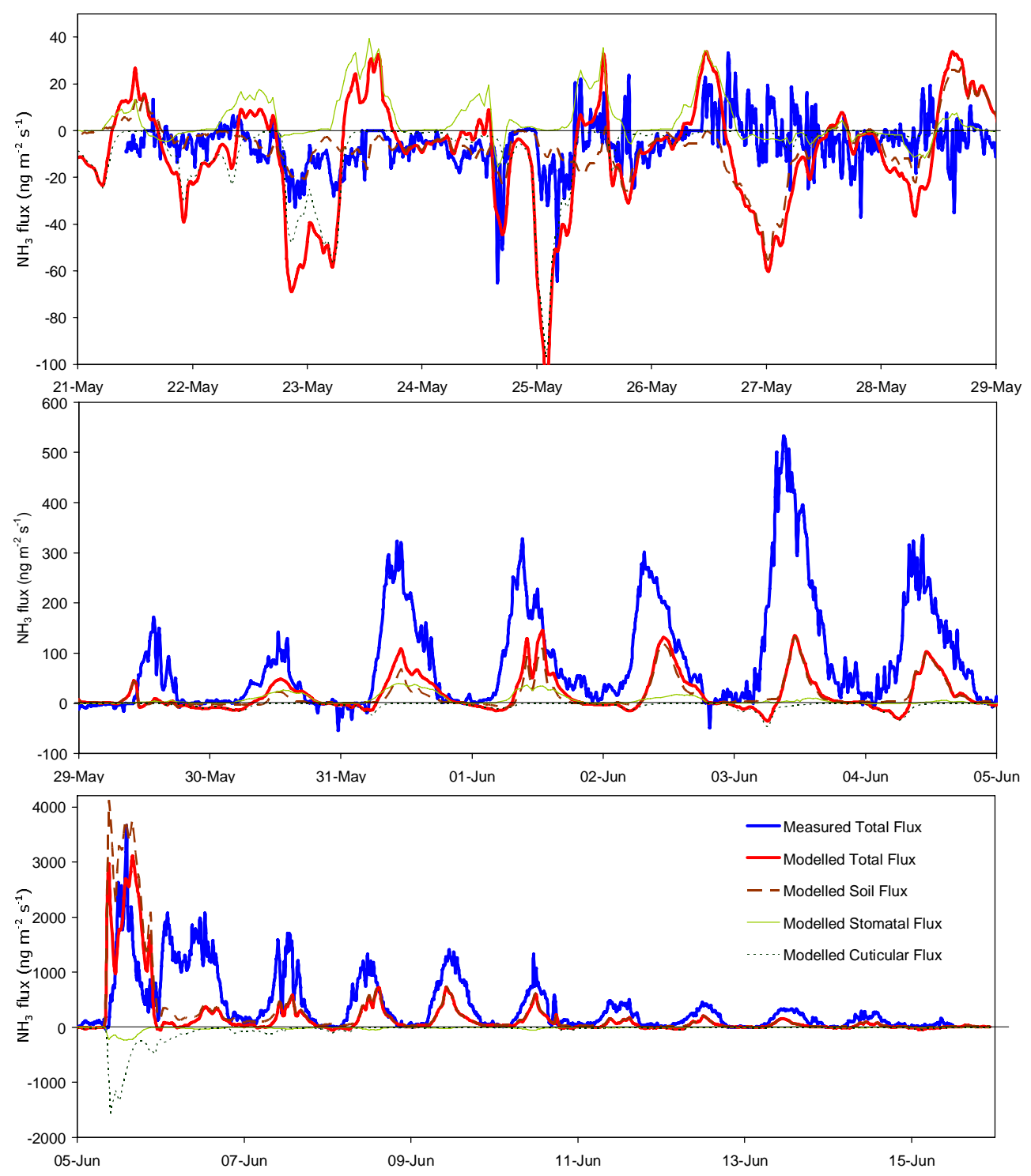

Fig. 11. Time course of component $\mathrm{NH}_{3}$ fluxes through the Braunschweig Experiment simulated by PaSim (base simulation) as compared with measured net fluxes $\left(F_{m g}\right)$.

of the measured soil $\left[\mathrm{NH}_{4}^{+}\right]$, which would have masked vertical gradients $(0$ to $0.1 \mathrm{~m}$ ) occurring immediately after fertilization. The simulated $\mathrm{NH}_{3}$ flux for the litter emission scenario is compared with the measured flux $\left(F_{m g}\right)$ in Fig. 12. This parametrization shows close agreement with the measurements, except for 8-10 June, when the model overestimated the measurements. These days had high soil surface temperatures (maxima: 35 to $45^{\circ} \mathrm{C}$ ). During these conditions, it is likely that soil surface/litter $\mathrm{NH}_{4}^{+}$would have been depleted due to $\mathrm{NH}_{3}$ emission, thereby limiting subsequent measured fluxes.

These model comparisons illustrate how temperature is one of the main drivers of net ammonia exchange, and this is even more clearly shown by Fig. 13, which compares the response of estimated ammonia fluxes to canopy temperature. In Fig. 13a, the fluxes measured by the gradient method $\left(F_{m g}\right)$ are plotted for each of the three main vegetation periods. By showing the lines that link adjacent $15 \mathrm{~min}$ values, it is clear that the data cluster for different days, with temperature being closely related to the diurnal pattern of ammonia fluxes. A similar pattern is seen in Fig. 13b, for the PaSim estimate of the fluxes, where there is a clear temperature response, with the data clustered according to different days, representing underlying differences in the emission potentials. While Fig. 13a and b show rather scattered responses, Fig. 13c illustrates the SURFATM- $\mathrm{NH}_{3}$ (litter scenario) estimates, which have a much more precise dependence on canopy 

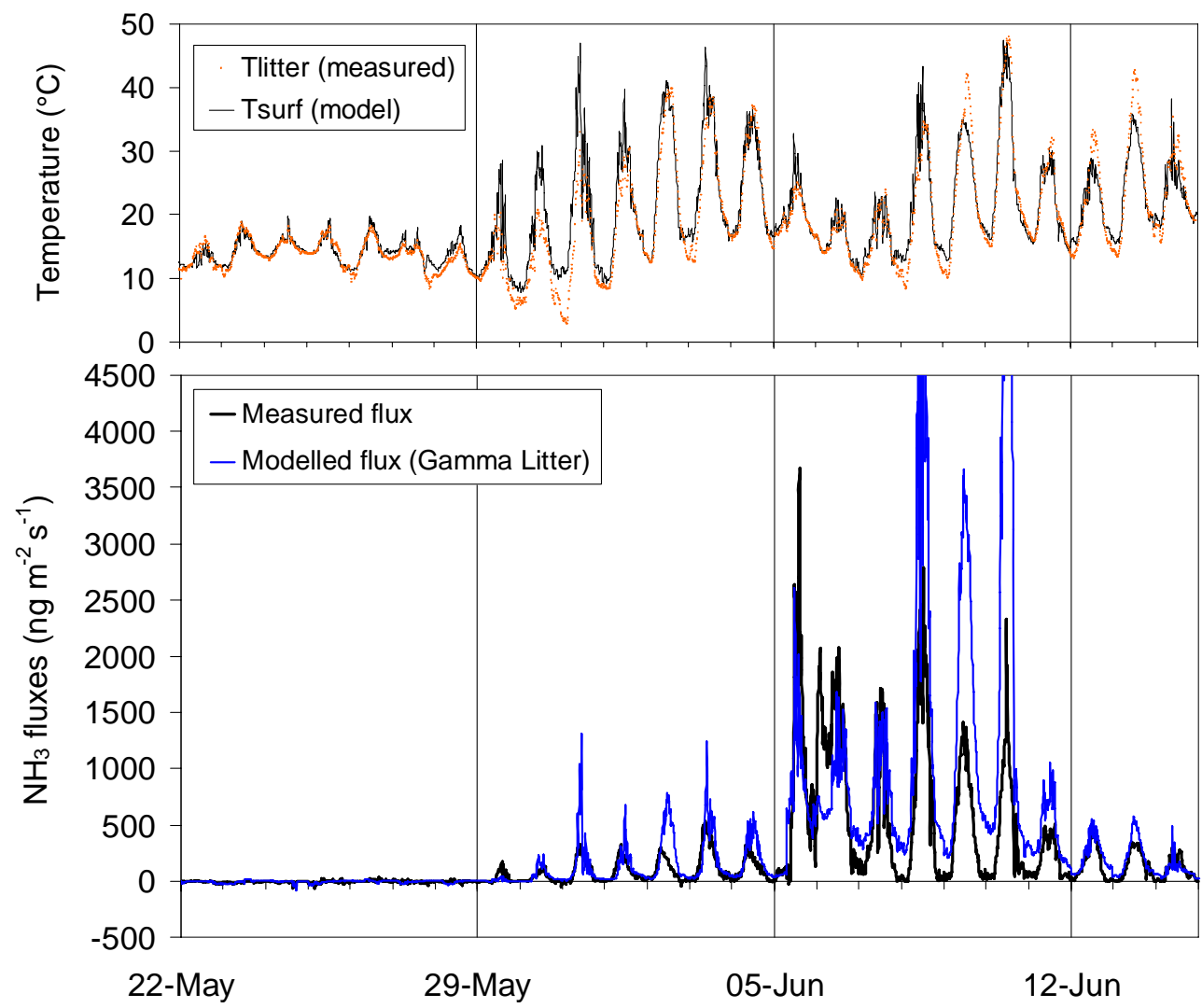

Fig. 12. Comparison of ammonia fluxes simulated by the SURFATM-NH $\mathrm{N}_{3}$ model with measured fluxes $\left(F_{m g}\right)$ during the Braunschweig Experiment, as compared with modeled and measured ground surface temperature. In this scenario, ground fluxes are simulated based on

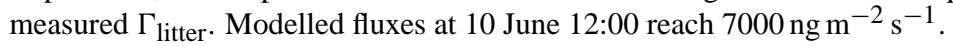

temperature. In this case, diurnal curves relate to the use of daily $\Gamma$ input values, based on the results of Fig. 7. Part of the additional scatter in Fig. 13a and b, can thus be related to the fact that, in reality, $\Gamma$ varies continuously.

\subsection{Application of the dynamic cuticular chemistry model}

The DCC model was applied by Burkhardt et al. (2009) to the pre-cut and post-cut periods to further investigate the role of leaf-surface chemical interactions. One of the first challenges in this approach is to estimate the leaf-surface water-film thickness. A series of clip sensors (Burkhardt and Eiden, 1994) recorded leaf electrical resistance in the field, which was empirically related to leaf surface moisture. The DCC model was re-initialized after rain using the measured rain chemistry, with $\Gamma_{s}$ set to 300 and $\Gamma_{\text {litter }}$ to 5200. The latter value was based on an earlier bioassay estimate, but was sufficient to explain the litter emissions where no value of $R_{d}$ is assumed (cf. Personne et al., 2009). While this reflects uncertainties in applying the models, the parametrization is sufficient to allow the DDC to explore leaf cuticle interactions.
An illustration of the simulation for the pre-cut period is shown in Fig. 14. The largest component emissions were from leaf litter $\left(F_{g}\right)$, most of which was estimated to be deposited to leaf surfaces $\left(F_{d}\right)$, with some uptake to stomata $\left(F_{s}\right)$. Although the values of $F_{d}$ in this example are almost all towards deposition (apart from briefly on 23 May), larger desorption fluxes would be expected in conditions of more-rapid drying. Figure 14 shows both the measured estimate of the flux $\left(F_{m g}(1 \mathrm{~m})\right)$ and the flux estimate at the surface, as corrected for advection effects $\left(F_{m g}\left(z_{o}\right)\right)$ using the FIDES model estimates. Although significant differences can be seen, it is evident that uncertainties associated with advection cannot explain the differences between the model and measurements.

The largest cuticular deposition was simulated for 25 May. This was partly related to increased turbulence and moisture, though the middle of the day was drier, reducing cuticular deposition and allowing modelled net emissions of $\mathrm{NH}_{3}$. This day is interesting in that the model qualitatively reproduces the dynamics of the measurements, though the temporal fluctuations in the measured fluxes are smaller. This may be due to a longer residence time for adsorption/desorption as regulated in the model by $R_{d}$, which 
remains a highly uncertain parameter (Sutton et al., 1998a; Flechard et al., 1999). The $R_{d}$ and $\chi_{d}$ values in the dynamic model dampen the fluctuations in modeled flux compared with use of $R_{w}$ in PaSim (c.f., Fig. 10a). In the DCC model, $R_{d}$ is parametrized as $\exp (\varepsilon I)$, where $I$ is ionic strength and $\varepsilon$ is 100 . Figure 14 illustrates a sensitivity run with $\varepsilon=400$, demonstrating how a larger $R_{d}$ has a significant effect on the modeled fluxes for some periods.

Burkhardt et al. (2009) also reported several sensitivity tests with the model. For the conditions of the Braunschweig Experiment, they found increasing $\mathrm{SO}_{2}$ concentrations only to have a small effect on the measured fluxes. By contrast, the model was more sensitive to the assumptions made about the potential for ion movement between the cuticle and apoplast (leaching and uptake), such as uptake of base cations which affects modeled leaf surface $\mathrm{pH}$. These interactions illustrate the complexity of $\mathrm{NH}_{3}$ exchange with plant canopies, and demonstrate the utility of such models in integrating the different driving factors.

\section{Conclusions}

The GRAMINAE Integrated Experiment conducted at Braunschweig has provided a comprehensive quantification of ammonia fluxes and the controlling processes. Overall, it proved possible to handle the multiple objectives of the experiment. The potential conflicts between objectives were assessed in advance and the layout of the experiment designed to minimize these (Sutton et al., 2009a). By contrast, incorporating multiple objectives had the benefit of allowing synergies to be addressed and a range of models to be tested.

At the outset of the experiment, five key questions were asked, and these form a useful framework to summarize the main conclusions.

\subsection{How do the component sources and sinks of ammonia exchange (leaf surfaces, leaf tissues, plant uptake from soil, litter decomposition) integrate to control net fluxes with the atmosphere?}

The combination of measurements and models applied to the Braunschweig Experiment highlight the multiple sources and sinks of ammonia within a grass canopy. At the outset, a high importance was given to estimation of bi-directional exchange through stomata with a compensation point $\left(\chi_{s}\right)$, with recapture of stomatal emissions by leaf surfaces, for example, parameterized by a cuticular resistance $\left(R_{w}\right)$. Analysis of the results during the Braunschweig Experiment reveals a different emphasis, highlighting the role of ammonia emissions from the leaf litter and the soil surface. The pattern of exchange is thus more similar to that observed by Denmead et al. (1976) and Nemitz et al. (2000) for grass-clover and oilseed rape canopies, respectively.
Mineralization of leaf litter on the soil surface appears to provide the primary ecosystem source for ammonia emission in this study. Prior to cutting of the grass, sheltering of the litter tends to reduce these emissions, with the emission being recaptured by the overlaying canopy. Thus although species differences in $\chi_{s}$ may be noted, these values become most important in affecting the recapture of litter ammonia emission.

Only under the condition of complete canopy recapture of the litter ammonia emissions, does the net flux with the atmosphere depend entirely on the values of $\chi_{s}$ and the interaction with cuticular uptake. However, for the Braunschweig experiment, periods of net ammonia emission before the cut cannot be explained by measured bioassay values of $\chi_{s}$, and must result from either (or a combination of) ammonia from the leaf litter escaping the canopy and desorption of ammonia temporarily deposited to leaf surfaces (as parametrized using $\chi_{d}$ and $R_{d}$ ). In principle, this can occur during drying conditions, after periods of moisture and large atmospheric ammonia concentrations $\left(\chi_{a}\right)$, though modelling suggested that such 'cuticular desorption' events only played a minor role during the experiment.

Overall, the canopy recapture of ammonia emitted from the surface appears to be reasonably well simulated by the models (PaSim, SURFATM-NH $\mathrm{N}_{3}$; DCC). By contrast, more work is required to simulate the dynamics of the ground surface emission. Although the empirical basis for ammonia emissions from leaf litter was demonstrated (SURFATM$\mathrm{NH}_{3}$, DCC), this process is not included in PaSim. Nemitz et al. (2000b) tested a simple model of leaf litter $\mathrm{NH}_{3}$ emission dynamics, and further research in this direction is needed.

The overall pattern of within-canopy and net ammonia fluxes is summarized in Fig. 15, which is based on average day and night-time values from the SURFATM- $\mathrm{NH}_{3}$ model. Prior to cutting, the foliage (stomata and cuticles) are estimated to have been a net sink for both atmospheric and litter derived ammonia, with the canopy flux at $136 \%$ (day) and 200\% (night) of the ground emission flux. By contrast, following both cutting and fertilization, only a small fraction of the ground emission flux is estimated to have been recaptured, with values of $13 \%$ (post-cut) and $17 \%$ (post-fertilization) recapture for daytime. For night time, $33 \%$ (post-cut) and 34\% (post-fertilization) of the ground emissions are estimated to have been recaptured. While these recapture rates may appear modest, it should be remembered that the sheltering effect of the canopy probably also reduced the magnitude of the ground ammonia source compared with a bare soil surface.

\subsection{What are the mechanisms by which grassland management events (cutting and $\mathbf{N}$ fertilization) affect component and net ammonia fluxes?}

Increased ammonia emissions lasting for several weeks after cutting have been demonstrated in several studies (e.g., 

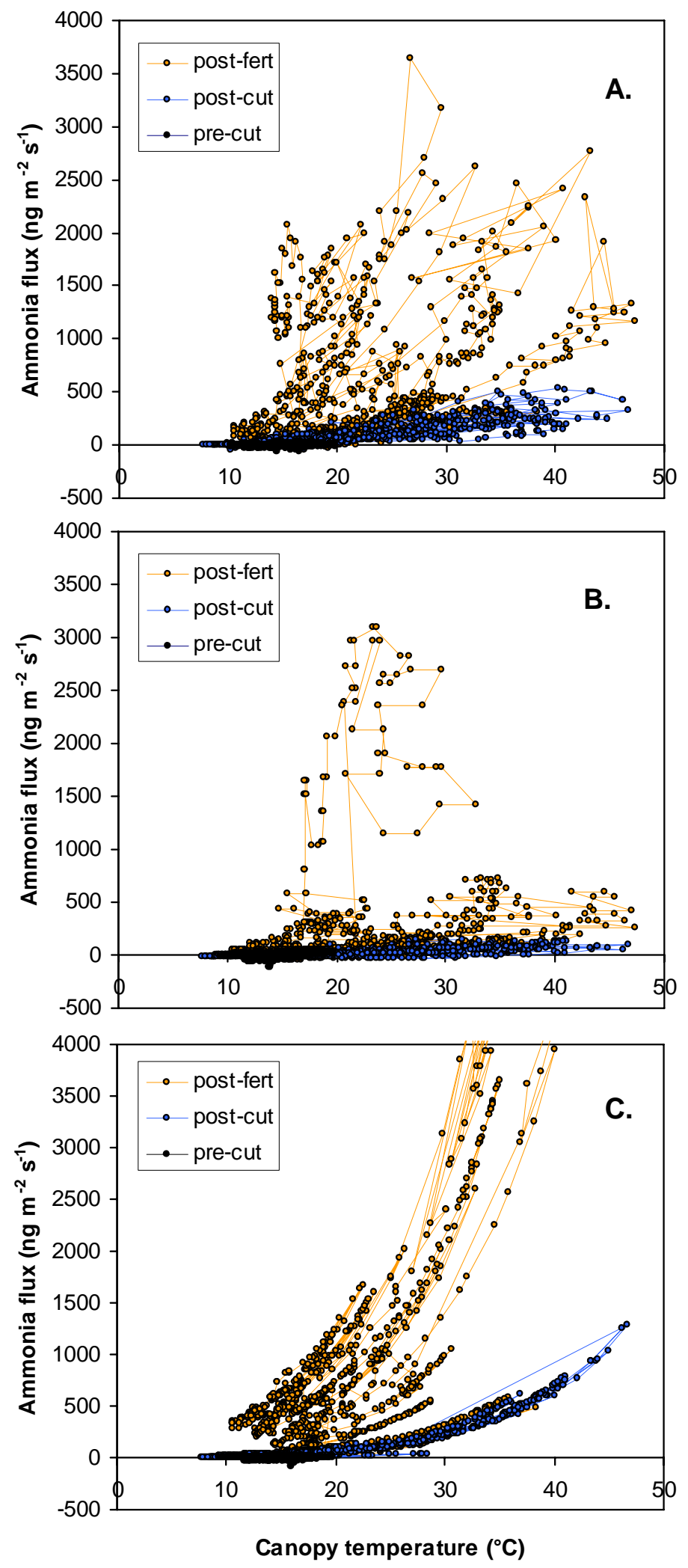

Fig. 13. Relationship between canopy-scale net ammonia fluxes and canopy temperature (estimated by SURFATM-NH 3 ) for the three vegetation periods of the GRAMINAE Experiment: (A): Fluxes measured according to the gradient method; (B): Fluxes modeled using PaSim; (C): Fluxes modeled using SURFATM-NH 3 (litter scenario). The joined points indicate continuous 15 min estimates. 


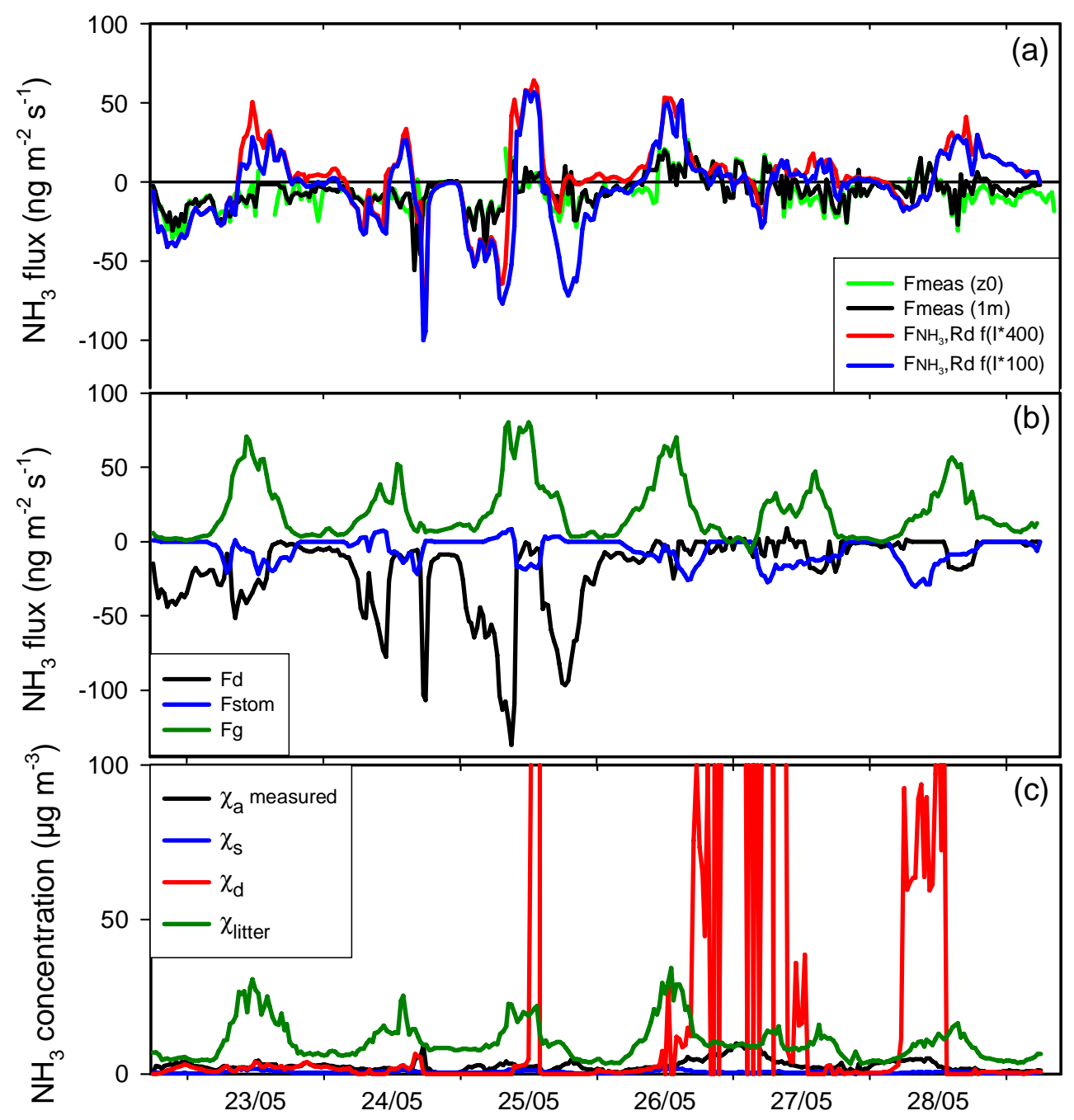

Fig. 14. (a) Ammonia fluxes simulated for the pre-cut period of the Braunschweig Experiment using the dynamic leaf cuticular chemistry model, as compared with the measured flux $\left(F_{m g}\right)$ at $1 \mathrm{~m}$ and at $z_{o}$ as corrected for advection using the FIDES model. The model base run (Burkhardt et al., 2009) applied the cuticular adsorption/desorption resistance $\left(R_{d}\right)$ as a function of $100 *$ ionic strength $(I)$. A sensitivity test is shown here for $R_{d}$ as $\mathrm{f}\left(400^{*} I\right)$. (b) The component fluxes for the base run: $F_{d}$, cuticular flux; $F_{s}$, stomatal flux; $F_{g}$, ground flux. (c) Measured air concentration $\left(\chi_{a}\right)$ is compared with the modeled surface concentrations for stomata $\left(\chi_{s}\right)$, leaf surface $\left(\chi_{d}\right)$ and the litter $\left(\chi_{s}\right)$ as estimated in the model base run.

Sutton et al., 1998b; Milford et al., 2001), and these have been attributed to a cutting-induced remobilization of plant nitrogen, related to a reduced carbon sink for plant substrate nitrogen (e.g., Loubet et al., 2002; Riedo et al., 2002). The Braunschweig Experiment showed a similar increase in ammonia emissions after cutting, but here bioassays showed no evidence of this increase being related to values of substrate nitrogen, or to $\Gamma_{s}$ driven values of $\chi_{s}$. At Braunschweig, the increased emissions can be fully explained (e.g., SURFATM-NH${ }_{3}$ ) by removal of the overlaying canopy allowing ammonia released from litter to reach the atmosphere. In parallel, $\Gamma_{\text {litter }}$ increased by a factor of 2-7 after cutting, presumably related to cutting-induced senescence, while warmer weather, combined with greater microclimatic fluctuations at the exposed soil/litter surfaces, would have promoted the litter-based emissions.

As expected, ammonia emissions increased substantially following fertilization, amounting to $3.2 \%$ of the $\mathrm{N}$ applied (equivalent to $3.6 \%$ if the post-cutting emissions are included, Milford et al., 2009). The PaSim and SURFATM$\mathrm{NH}_{3}$ models both highlight that most of this emission is of surface origin (soil surface and litter), rather than emission mediated via stomata. Even though there are measurement uncertainties, bioassay estimates of $\Gamma_{s}$ were at least an order of magnitude smaller than required to account for net emissions. This indicates that stomata (together with the leaf surfaces) represented a sink to recapture part of the ground source $\mathrm{NH}_{3}$ emissions. 

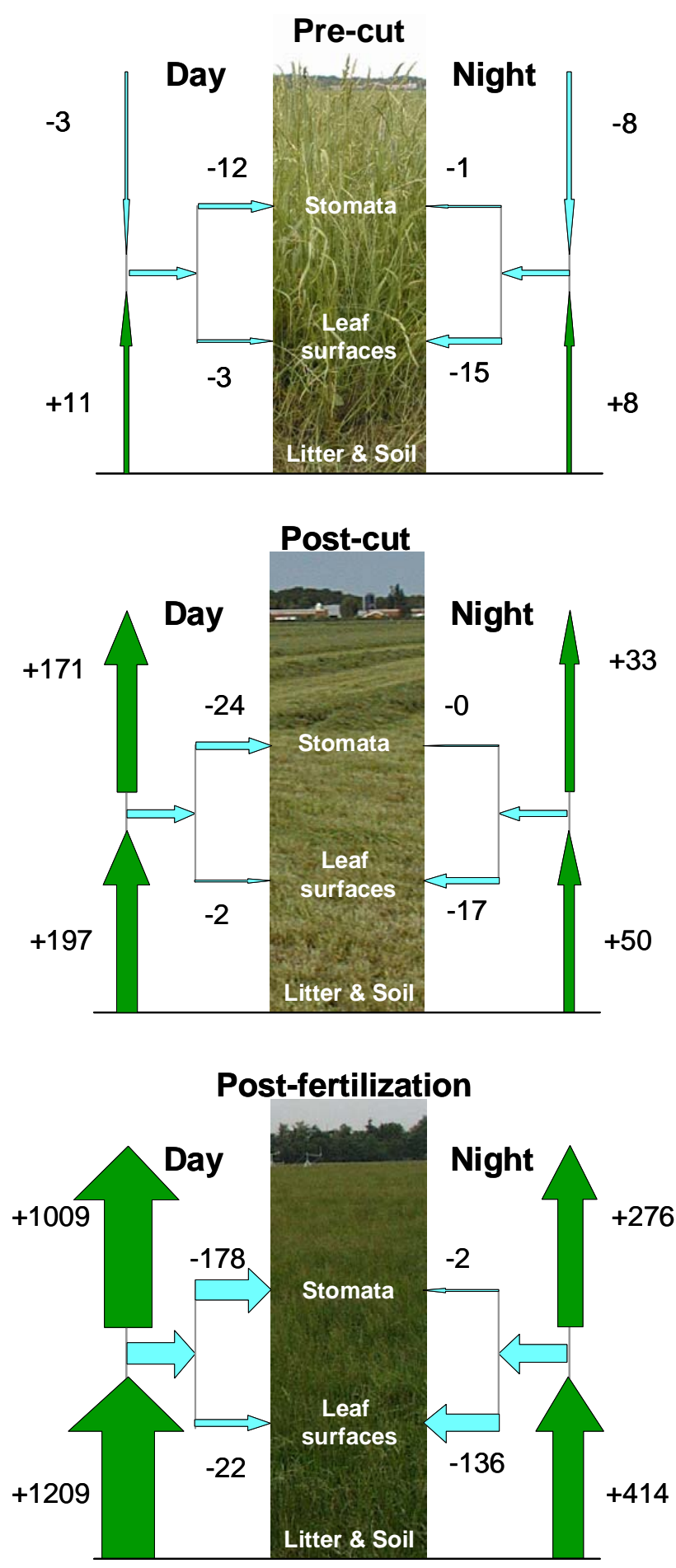

Fig. 15. Mean component and net ammonia fluxes through the three vegetation periods of the GRAMINAE Experiment, contrasting day and night conditions, as estimated with the SURFATM-NH $\mathrm{NH}_{3}$ model parametrization of the measured fluxes (fluxes in $\mathrm{n} \mathrm{m}^{-2} \mathrm{~s}^{-1} \mathrm{NH}_{3}$ ).
The soil and bioassay measurements suggest that the applied fertilizer is absorbed by leaf litter in addition to the soil surface. The leaf litter thus represents a reservoir for later $\mathrm{NH}_{3}$ emission from the fertilizer, which adds to the contribution from litter mineralization. However, the relative contribution of the soil surface and litter to postfertilization emissions remains uncertain from the available measurements. Although PaSim does not distinguish this partitioning onto leaf litter, it performs reasonably in highlighting the overall increase and subsequent reduction in emissions for 10 days after fertilization. However, further work is required to simulate more realistically the processes of fertilizer dissolution and partitioning at the soil/litter surface, especially in relation to varying water and temperature regimes.

\subsection{When does the location of a micrometeorological study site in a real landscape lead to significant quantifiable effects of advection on net ammonia fluxes and their measurement?}

The design of the Braunschweig experiment allowed locations to be chosen that could directly quantify the effects of advection on vertical ammonia fluxes. In this case, the flux measurement sites were $550 \mathrm{~m}$ and $750 \mathrm{~m}$ to the east of a mixed livestock farm housing 380 cattle and 170 pigs. Combined with measurements of horizontal ammonia concentration profiles downwind of the farm, and profiles measured across the main wind direction, it was possible to use two inverse dispersion models (Gaussian model, FIDES dispersion deposition model) to estimate the magnitude of emissions from the farm and their influence on ammonia dispersion and deposition. Overall, the model estimates of ammonia emissions from the farm at $6-9 \mathrm{~kg} \mathrm{NH}$ day $^{-1}$ were in realistic agreement with inventory estimates $\left(10 \mathrm{~kg} \mathrm{NH}_{3}\right.$ day $\left.^{-1}\right)$. Modelled advection errors in the vertical flux (estimated at the main flux measurement site $550 \mathrm{~m}$ downwind) were in the range 0 to $27 \mathrm{ng} \mathrm{m}^{-2} \mathrm{~s}^{-1}$, while measured values (from the horizontal concentration profiles) were similar ( 0 to $35 \mathrm{ng} \mathrm{m}^{-2} \mathrm{~s}^{-1}$ ). These values were small compared with the magnitude of ammonia emissions from this field for most of the experiment, but represent a significant correction for the relevant wind directions for the pre-cut period. The results are also illustrative of the magnitude of advection effects for other situations, highlighting the importance of quantifying advection effects when assessing the rates of ammonia deposition to semi-natural ecosystems occurring in rural landscapes (cf. Loubet et al., 2001; Milford et al., 2001a). The overall effect of the relevant corrections is to increase estimated rates of ammonia deposition compared with uncorrected flux measurements or inferential modelling.

A further finding of the Braunschweig Experiment revealed by the measurements of horizontal ammonia concentration profiles and the FIDES model (see Fig. 3) is 
that the emissions from the field itself can induce advection errors in the measured vertical fluxes. Measured and modelled values were in the range -209 to 0 and -60 to $0 \mathrm{ng} \mathrm{m}^{-2} \mathrm{~s}^{-1}$, respectively. Although these are larger than the advection resulting from the farm, because they are generated by high ammonia emissions from the field, with sufficient fetch they represent only a small relative correction to the measured fluxes.

\subsection{How much does the near-surface perturbation of the equilibria between ammonia, acid gases and aerosols lead to non-conservation of vertical ammonia fluxes, and is this a relevant mechanism for particle production?}

The Braunschweig Experiment has highlighted the role of atmospheric reactions in the surface layer due to surface concentration profiles of ammonia and nitric acid interacting with profiles of temperature and relative humidity. In the period after fertilization, the concentration product $\left[\mathrm{NH}_{3}\right]\left[\mathrm{HNO}_{3}\right]$ frequently exceeded the equilibrium for formation of particulate $\mathrm{NH}_{4} \mathrm{NO}_{3}$. The signal of this effect was clearly detected from eddy covariance (EC) particle number fluxes using a Condensation Particle Counter (CPC), which showed apparent particle emissions to be correlated to periods of large ammonia emission.

The analysis of Nemitz et al. (2009a) shows that these apparent upward aerosol fluxes were the result of particle growth due to $\mathrm{NH}_{3}$ and $\mathrm{HNO}_{3}$ condensation onto existing aerosol, so that particles grew to larger than the lower size limit for detection by the CPC. Based on the measurements, Nemitz et al. (2009a) provide the first estimates of $\mathrm{NH}_{4} \mathrm{NO}_{3}$ formation from this near-surface (0 to $2 \mathrm{~m})$ condensation process. These estimates have relevance in their own right, and show that the effect leads to mean errors in $\mathrm{NH}_{4}^{+}$ and $\mathrm{NO}_{3}^{-}$deposition fluxes of $4 \%$ and $10 \%$, for day and night, respectively. By contrast, the effect results in small corrections to the measured ammonia fluxes of $0.06 \%$ and $0.56 \%$ for day and night, respectively.

The measurements demonstrate that gas-particle interactions during the Braunschweig Experiment had a trivial effect on the conservation of ammonia fluxes with height. In the present case, the flux corrections can effectively be ignored for ammonia, though they remain relevant for the aerosol fluxes. Nevertheless, such effects may still be relevant in other conditions. For example, Brost et al. (1988) simulated significant interactions downwind of a farm installation, while Nemitz and Sutton (2004) simulated the effect of high surface temperatures combined with $\mathrm{NH}_{3}$ and $\mathrm{HNO}_{3}$ deposition to a semi-natural ecosystem. In the latter case, particle evaporation was estimated to affect measured trace gas fluxes. The present observation of apparent particle emissions highlights the need to consider chemical interactions when deriving deposition velocity parametrizations from field measurements.

\subsection{To what extend can divergence in vertical ammonia fluxes (either due to advection or chemical reactions) be directly measured by available techniques?}

In order to measure vertical flux divergence directly, measurements are needed that can quantify ammonia flux using sampling at one point, such as relaxed eddy accumulation (REA) and EC, as contrasted against the aerodynamic gradient method (AGM), which estimates fluxes based on measurements at several heights. The development and inter-comparison of several REA implementations for ammonia reported by Hensen et al. (2009b) provided a precision that was in several cases comparable with the AGM, but not sufficient to detect the expected flux divergences due to gas-particle reactions. Based on the subsequent analysis of Nemitz et al. (2009a), this becomes clear given the very small net effect of gas-particle reactions on net ammonia fluxes (Sect. 5.4).

Depending on the experimental set up and the occurrence of nearby farm sources, flux divergence due to advection effects may be larger and therefore easier to measure. For example, if several of the REA methods had been deployed at $340 \mathrm{~m}$ from the farm, the prior modelling (Fig. 2 in Sutton et al., 2009a) indicates that advection may alter a flux at canopy level of $-200 \mathrm{ng} \mathrm{m}^{-2} \mathrm{~s}^{-1}$ to values of around 160 and $110 \mathrm{ng} \mathrm{m}^{-2} \mathrm{~s}^{-1}$ at $0.5 \mathrm{~m}$ and $1.5 \mathrm{~m}$ above the canopy, respectively. Such differences should be detectable both with the REA implementations (see Fig. 5) and with current eddy covariance systems using TDLAS (e.g. Whitehead et al., 2008). Thus, where it is of interest to estimate ammonia fluxes in situations very close to ammonia sources (c.f., Cape et al., 2008), and several inter-calibrated REA or EC systems are available, it would be feasible to quantify directly and correct for ammonia advection effects. Nevertheless, the flux inter-comparisons of this study highlight that improved precision and reliability in the detectors used for ammonia flux measurement must be considered the future priority.

Acknowledgements. The authors gratefully acknowledge the support of many different funders and colleagues to this work. The measurements were conducted under the frame of the GRAMINAE project funded by the European Commission (DG Research), with input from a wide range of national funding agencies, in particular the UK Defra (AEQ Division). The final analysis of results was conducted under the EC NitroEurope Integrated Project, with travel support from ACCENT and the ESF NinE and COST 729 programmes.

Edited by: K. Pilegaard 


\section{References}

Achermann, B. and Bobbink, R. (Eds.): Empirical critical loads for Nitrogen. SAEFL, Berne, Switzerland, 2003.

Amann, M., Bertok, I., Cofala, J., Gyarfas, F., Heyes, C., Klimont, Z., Schöpp, W., and Winiwarter, W.: Baseline Scenarios for the Clean Air for Europe (CAFE) Programme. IIASA, Laxenburg, Austria, online available at: www.iiasa.ac.at/rains/CAFE_files/ CAFE-baseline-full.pdf, 2005.

Bigg, E. K.: Gas emissions from soil and leaf litter as a source of new particle formation, Atmos. Res., 70, 33-42, 2004.

Brost, R. A., Delany, A. C., and Huebert, B. J.: Numerical modeling of concentrations and fluxes of $\mathrm{HNO}_{3}, \mathrm{NH}_{3}$, and $\mathrm{NH}_{4} \mathrm{NO}_{3}$ near the surface, J. Geophys. Res., 93, 7137-7152, 1988.

Burkhardt, J. and Eiden, R. Thin water films on coniferous needles. Atmos. Environ. 28A, 2002-1019, 1994.

Burkhardt, J., Flechard, C. R., Gresens, F., Mattsson, M., Jongejan, P. A. C., Erisman, J. W., Weidinger, T., Meszaros, R., Nemitz, E., and Sutton, M. A.: Modelling the dynamic chemical interactions of atmospheric ammonia with leaf surface wetness in a managed grassland canopy, Biogeosciences, 6, 67-83, 2009, http://www.biogeosciences.net/6/67/2009/.

Cape, J. N., Jones, M. R., Leith, I. D., Sheppard, van Dijk, N., Sutton, M. A., and Fowler, D.: Estimate of annual $\mathrm{NH}_{3}$ dry deposition to a fumigated ombrotrophic bog using concentrationdependent deposition velocities, Atmos. Environ. 42, 66376646, 2008.

Cellier, P., Richard, G., and Robin, P.: Partition of sensible heat fluxes into bare soil and the atmosphere, Agr. Forest Meteorol., 82, 245-265, 1996.

Choudhury, B. J. and Monteith, J. L.: A four-layer model for the heat budget of homogeneous land surfaces. Quart. J. Roy. Meteorol. Soc., 114, 373-398, 1988.

David, M., Loubet, B., Cellier, P., Mattsson, M., Schjoerring, J.K., Nemitz, E., Roche, R., Riedo, M., and Sutton, M. A.: Ammonia sources and sinks in an intensively managed grassland, Biogeosciences, 6, 1903-1915, 2009a.

David, M., Roche, R., Mattsson, M., Sutton, M. A., Dämmgen, U., Schjoerring, J. K., and Cellier, P.: The effects of management on ammonia fluxes over a grassland as measured by use of dynamic chambers, Biogeosciences Discuss., 6, 1599-1623, 2009b, http://www.biogeosciences-discuss.net/6/1599/2009/.

Davidson, C. I., Phalen, R. F., and Solomon, P. A.: Airborne Particulate Matter and Human Health: A Review, Aerosol Sci. Tech. 39, 737-749, 2005.

de Vries, W., Solberg, S., Dobbertin, M., Sterba, H., Laubhahn, D., Reinds, G. J., Nabuurs, G.-J., Gundersen, P., and Sutton, M. A.: Ecologically implausible carbon response?, Nature, 451, E1-E3, doi:10.1038/nature06579, 2008.

Demmers, T. G. M., Burgess, L. R., Short, J. L., Phillips, V. R., Clark, J. A., and Wathes, C. M.: Ammonia emissions from two mechanically ventilated UK livestock buildings. Atmos. Environ., 33, 107-116, 1999.

Denmead, O. T., Freney, J. R., and Simpson, J. R.: A closed ammonia cycle within a plant canopy, Soil Sci. Biochem. 8, 161164, 1976.

Döhler, H., Dämmgen, U., Berg, W., Bergschmidt, A., Brunsch, R., Eurich-Menden, B., Lüttich, M., and Osterburg, B.: Adaptation of the German emission calculation methodology to international guidelines, determination and forecasting of ammonia emissions from German agriculture, and scenarios for reducing them by 2010 (German, English summary), Umweltbundesamt, Berlin, Germany, 2002.

Dragosits, U., Theobald, M. R., Place, C. J., Lord, E., Webb, J., Hill, J., ApSimon, H. M., and Sutton, M. A.: Ammonia, emission, deposition and impact assessment at a field scale: a case study of sub-grid spatial variability, Environ. Poll., 117, 147-158, 2002.

Duyzer, J. H., Nijenhuis, B., and Weststrate, H.: Monitoring and modelling of ammonia concentrations and deposition in agricultural areas of the Netherlands, Water Air Soil Pollut: Focus 1, 131-144, 2001.

Erisman J. W. and Sutton M. A.: Reduced nitrogen in ecology and the environment: Special issue of the ESF-FWF Conference in partnership with LFUI, Environ. Pollut., 154, 357-358, 2008 a.

Erisman, J. W., Sutton, M. A., Galloway, J. N., Klimont, Z., and Winiwarter, W.: How a century of ammonia synthesis changed the world. Nature Geosci., 1, 636-639, 2008b.

Famulari, D., Fowler, D., Hargreaves, K., Milford, C., Sutton, M. A., Nemitz, E., and Weston, K.: Measuring eddy-covariance fluxes of ammonia using tunable diode laser absorption spectroscopy, Water Air Soil Pollut. Focus, 4(6), 151-158, 2004.

Flechard, C., Fowler, D., Sutton, M. A., and Cape, J. N.: A dynamic chemical model of bi-directional ammonia exchange between semi-natural vegetation and the atmosphere, Q. J. Roy. Meteor. Soc., 125, 2611-2641, 1999.

Hensen, A., Nemitz, E., Flynn, M. J., Blatter, A., Jones S. K., Sørensen, L. L., Hensen, B., Pryor, S., Jensen, B., Otjes, R. P., Cobussen, J., Loubet, B., Erisman, J. W., Gallagher, M. W., Neftel, A., and Sutton M. A.: Inter-comparison of ammonia fluxes obtained using the Relaxed Eddy Accumulation technique, Biogeosciences, 6, 2575-2588, 2009a, http://www.biogeosciences.net/6/2575/2009/.

Hensen, A., Loubet, B., Mosquera, J., van den Bulk, W. C. M., Erisman, J. W., Dämmgen, U., Milford, C., Löpmeier, F. J., Cellier, P., Mikuska, P., Sutton, M. A.: Estimation of $\mathrm{NH}_{3}$ emissions from a naturally ventilated livestock farm using local-scale atmospheric dispersion modelling, Biogeosciences, 6, 2847-2860, 2009b, http://www.biogeosciences.net/6/2847/2009/.

Herrmann, B., Mattsson, M., Jones, S. K., Cellier, P., Milford, C., Sutton, M. A., Schjoerring, J. K., and Neftel, A.: Vertical structure and diurnal variability of ammonia exchange potential within an intensively managed grass canopy, Biogeosciences, 6 , 15-23, 2009, http://www.biogeosciences.net/6/15/2009/.

Hertel, O., Skjøth, C. A., Lofstrøm, P., Geels, C., Frohn, L. M., Ellermann, T., and Madsen, P. V.: Modelling nitrogen deposition on a local scale - A review of the current state of the art. Environ. Chem. 3, 317-337, 2006.

Husted, S., Hebbern, C. A., Mattsson, M., and Schjoerring, J. K.: A critical experimental evaluation of methods for determination of $\mathrm{NH}_{4}^{+}$in plant tissue, xylem sap and apoplastic fluid, Physiol. Plantarum, 109(2), 167-179, 2000a.

Husted, S., Schjoerring, J. K., Nielsen, K. H., Nemitz, E., and Sutton, M. A.: Stomatal compensation points for ammonia in oilseed rape plants under field conditions, Agr. For, Meteorol., 105, 371-383, $2000 b$.

Husted, S., Mattsson, M. Möllers, C., Wallbraun, M., and Schjoerring, J. K.: Photorespiratory $\mathrm{NH}_{4}^{+}$production in leaves of wildtype and GS2-antisense oilseed rape, Plant Physiol., 130, 
989-998, 2002.

Jarvis, P. G.: The interpretation of the variation in leaf water potential and stomatal conductance found in canopies in the field, Phil. Trans. Roy. Soc. London, B273, 593-610, 1976.

Keuken, M. P., Schoonebeek, C. A. M., van Wensveen-Louter, A., and Slanina, J.: Simultaneous sampling of $\mathrm{NH}_{3}, \mathrm{HNO}_{3}$, $\mathrm{HCl}, \mathrm{SO}_{2}$ and $\mathrm{H}_{2} \mathrm{O}_{2}$ by a wet annular denuder system, Atmos. Environ., 22, 2541-2548, 1988.

Kulmala, M., Vehkamaki, H., Petajda, T., Dal Maso, M., Lauri, A., Kerminen, V. M., Birmil, W., and McMurry, P. H.: Formation and growth rates of ultrafine atmospheric particles: a review of observations, J. Aerosol Sci., 35(2), 143-176, 2004.

Laubach, J. and Teichmann, U.: Surface energy budget variability: A case study over grass with special regard to minor inhomogeneities in the source area, Theoret. Appl. Climatol., 62, 9-24, 1999.

Lehmann, B. E., Hehmann, M., Neftel, A., and Tarakanov, S. V.: Radon-220 calibration of near surface turbulent gas transport, Geophys. Res. Lett., 26(5), 607-610, 1999.

Loubet, B., Asman, W. A. H., Theobald, M. R., Hertel, O., Tang, Y. S., Robin, P., Hassouna, M., Daemmgen, U., Genermont, S., Cellier, P., and Sutton, M. A.: Ammonia deposition near hot spots: processes, models and monitoring methods, in: Atmospheric Ammonia: Detecting emission changes and environmental impacts edited by: Sutton, M. A., Baker, S., and Reis, S., 205-267, Springer, 2009a.

Loubet, B., Cellier, P., Milford, C., and Sutton, M. A.: A coupled dispersion and exchange model for short-range dry deposition of atmospheric ammonia, Q. J. Roy. Meteor. Soc., 132, 1733-1763, 2006.

Loubet, B., Milford, C., Hill, P. W. Tang, Y. S., Cellier, P., and Sutton, M. A.: Seasonal variability of apoplastic $\mathrm{NH}_{4}^{+}$and $\mathrm{pH}$ in an intensively managed grassland, Plant Soil, 238, 97-110, 2002.

Loubet, B., Milford, C., Hensen, A., Dämmgen, U., Cellier, P., and Sutton, M. A.: Advection of ammonia over a pasture field, and its effect on gradient flux measurements, Biogeosciences, 6, 12951309, 2009b.

Loubet, B., Milford, C., Sutton, M. A., and Cellier, P.: Investigation of the interaction between sources and sinks of atmospheric ammonia in an upland landscape using a simplified dispersionexchange model, J. geophys Res., 106, 24183-24195, 2001.

Magnani, F., Mencuccini, M., Borghetti, M., Berbigier, P., Berninger, F., Delzon, S., Grelle, A., Hari, P., Jarvis, P. G., Kolari, P., Kowalski, A. S., Lankreijer, H., Law, B. E., Lindroth, A., Loustau, D., Manca, G., Moncrieff, J. B., Rayment, M., Tedeschi, V., Valentini, R., and Grace, J.: The human footprint in the carbon cycle of temperate and boreal forests, Nature, 447, 848-850, 2007.

Mattsson M., Herrmann B., David M., Loubet B., Riedo M., Theobald M.R., Sutton M.A.,

Bruhn D., Neftel A. and Schjoerring J.K.: Temporal variability in bioassays of the stomatal ammonia compensation point in relation to plant and soil nitrogen parameters in intensively managed grassland. Biogeosciences, 6, 171-179, 2009a, http://www.biogeosciences.net/6/171/2009/.

Mattsson, M., Herrmann, B., Jones, S. K, Neftel, A., Sutton, M. A., and Schjoerring, J. K.: Contribution of different grass species to plant-atmosphere ammonia exchange in intensively managed grassland. Biogeosciences, Biogeosciences, 6, 59-66, 2009b, http://www.biogeosciences.net/6/59/2009/.

Mattsson, M. and Schjoerring, J. K.: Dynamic and steady state responses of inorganic nitrogen pools and $\mathrm{NH}_{3}$ exchange in leaves of Lolium perenne and Bromus erectus to changes in root N supply, Plant Physiol., 128, 742-750, 2002.

Mattsson, M. and Schjoerring, J. K.: Senescence-induced changes in apoplastic and bulk tissue ammonia concentrations of ryegrass leaves, New Phytol., 160(3) 489-499, 2003.

Mészáros, R., Horváth, L. Weidinger, T., Neftel, A., Nemitz, E., Dämmgen, U., Cellier, P., and Loubet, B.: Measurement and modelling ozone fluxes over a cut and fertilised grassland, Biogeosciences, 6, 1987-1999, 2009.

Milford, C., Hargreaves, K. J., Sutton, M. A., Loubet, B. and Cellier, P.: Fluxes of $\mathrm{NH}_{3}$ and $\mathrm{CO}_{2}$ over upland moorland in the vicinity of agricultural land, J. geophys Res. Atmos., 106, 24169-24181, 2001a.

Milford, C., Theobald, M. R., Nemitz, E., and Sutton, M. A.: Dynamics of ammonia exchange in response to cutting and fertilizing in an intensively-managed grassland, Water Air Soil Poll. Focus, 1, 167-176, 2001b.

Milford, C., Theobald, M. R.., Nemitz, E., Hargreaves, K. J., Horvath, L., Raso, J., Dämmgen, U., Neftel, A., Jones, S. K., Hensen, A., Loubet, B., and Sutton, M. A.: Ammonia fluxes in relation to cutting and fertilization of an intensively managed grassland derived from an inter-comparison of gradient measurements, Biogeosciences, 6, 819-834, 2009.

Misselbrook, T. H., Nicholson, F. A., Chambers, B. J., and Johnson, R. A.: Measuring ammonia emissions from land applied manure: an intercomparison of commonly used samplers and techniques, Environ. Poll., 135, 389-397, 2005.

Neftel, A., Blatter, A., Otjes, R., Erisman, J. W., and Hensen, A.: State of the art REA $\mathrm{NH}_{3}$ flux measurements. In: Proc. 10th Nitrogen Workshop, Copenhagen, August 1999. II.49. Royal Veterinary and Agricultural University, Copenhagen, Denmark, 1999.

Nemitz, E., Dorsey, J. R., Flynn, M. J., Gallagher, M. W., Hensen, A., Owen, S., Dämmgen, U., and Sutton, M. A.: Aerosol fluxes and particle growth above managed grassland, Biogeosciences, 6, 1627-1645, 2009a.

Nemitz, E., Flynn, M., Williams, P. I., Milford, C., Theobald, M. R., Blatter, A., Gallagher, M. W., and Sutton, M. A.: A relaxed eddy accumulation system for the automated measurement of atmospheric ammonia fluxes, Water Air Soil Pollut. Focus 1, 189-202, 2001a.

Nemitz, E., Hargreaves, K. J., Neftel, A., Loubet, B., Cellier, P., Dorsey, J. R., Flynn, M., Hensen, A., Weidinger, T., Meszaros, R., Horvath, L., Dämmgen, U., Fruehauf, C., Löpmeier F. J., Gallagher, M. W., and Sutton, M. A.: Inter-comparison and assessment of turbulent and physiological exchange parameters of grassland, Biogeosciences, 6, 1445-1466, $2009 \mathrm{~b}$.

Nemitz, E., Loubet, B., Lehmann, B. E., Cellier, P., Neftel, A., Jones, S. K., Hensen, A., Ihly, B., Tarakanov, S., and Sutton, M. A.: Turbulence characteristics and transport mechanisms in grassland canopies, Biogeosciences, 6, 1519-1537, 2009c

Nemitz, E., Milford, C., and Sutton, M. A.: A two-layer canopy compensation point model for describing bi-directional biosphere/atmosphere exchange of ammonia, Q. J. Roy. Meteor. Soc. $127,815-833,2001 b$.

Nemitz, E. and Sutton M. A.: Gas-particle conversions above a 
Dutch heathland: III. Modelling of size-dependent $\mathrm{NH}_{4}^{+}$fluxes as modified by the $\mathrm{NH}_{3}-\mathrm{HNO}_{3}-\mathrm{NH}_{4} \mathrm{NO}_{3}$ equilibrium, Atmos. Chem. Phys., 4, 1025-1045, 2004, http://www.atmos-chem-phys.net/4/1025/2004/.

Nemitz, E., Sutton, M. A., Gut, A., San José, R., Husted, S., and Schjoerring, J. K.: Sources and sinks of ammonia within an oilseed rape canopy, Agric. For. Meteorol, (Ammonia Special Issue), 105(4), 385-404, 2000a.

Nemitz, E., Sutton, M. A., Schjoerring, J. K., Husted, S., and Wyers, G. P.: Resistance modelling of ammonia exchange over oilseed rape, Agric. For. Meteorol. (Ammonia Special Issue) ,105 (4), 405-425, 2000b.

Personne, E., Loubet, B., Herrmann, B., Mattsson, M., Schjoerring, J. K., Nemitz, E., Sutton, M. A., and Cellier, P.: SURFATM$\mathrm{NH}_{3}$ : a model combining the surface energy balance and the bi-directional exchanges of ammonia at the field scale, Biogeosciences, 6, 1371-1388, 2009.

Riedo, M., Milford, C., Schmid, M., and Sutton, M. A.: Coupling soil-plant-atmosphere exchange of ammonia with ecosystem functioning in grasslands, Ecol. Model. 158, 83-110, 2002.

Schjoerring, J. K., Husted, S., and Mattsson, M.: Physiological parameters controlling plant-atmosophere ammonia exchange, Atmos. Environ. (Ammonia Special Issue) 32(3), 491-498, 1998.

Sutton, M. A. and Fowler, D.: A model for inferring bi-directional fluxes of ammonia over plant canopies. In: Proceedings of the WMO conference on the measurement and modelling of atmospheric composition changes including pollutant transport, World Meteorological Organization, Geneva, 179-182, 1993.

Sutton, M. A., Fowler, D., Moncrieff, J. B., and Storeton-West, R. L.: The exchange of atmospheric ammonia with vegetated surfaces. II: Fertilized vegetation, Q. J. Roy. Meteor. Soc., 119, 1047-1070, 1993.

Sutton, M. A., Burkhardt, J. K., Guerin, D., Nemitz, E., and Fowler, D.: Development of resistance models to describe measurements of bi-directional ammonia surface atmosphere exchange, Atmos. Environ. (Ammonia Special Issue) 32(3), 473-480, 1998a.

Sutton, M. A., Milford, C., Dragosits, U., Place, C. J., Singles, R. J., Smith, R. I., Pitcairn, C. E. R., Fowler, D., Hill, J., ApSimon, H. M., Ross, C., Hill, R., Jarvis, S. C., Pain, B. F., Phillips, V. C., Harrison, R., Moss, D., Webb, J., Espenhahn, S. E., Lee, D. S., Hornung, M., Ullyett, J., Bull, K. R., Emmett, B. A., Lowe, J., and Wyers, G. P.: Dispersion, deposition and impacts of atmospheric ammonia: quantifying local budgets and spatial variability, Environ. Pollut., 102, S1, 349-361b, 1998.

Sutton, M. A., Nemitz, E., Fowler, D., Wyers, G. P., Otjes, R. P., Schjoerring, J. K., Husted, S., Nielsen, K., San José, R., Moreno, J., Gallagher, M. W., and Gut, A.: Fluxes of ammonia over oilseed rape: Overview of the EXAMINE experiment, Agr. For. Meteorol. (Ammonia Special Issue) 105(4), 327-349, 2000.

Sutton, M. A., Milford, C., Nemitz, E., Theobald, M. R., Hill, P. W., Fowler, D., Schjoerring, J. K., Mattsson, M. E., Nielsen, K. H., Husted, S., Erisman, J. W., Otjes, R., Hensen, A., Mosquera, J., Cellier, P., Loubet, B., David, M., Genermont, S., Neftel, A., Blatter, A., Herrmann, B., Jones, S. K., Horvath, L., Führer, E., Mantzanas, K., Koukoura, Z., Gallagher, M., Williams, P., Flynn, M., and Riedo, M.: Biosphere-atmosphere interactions of ammonia with grasslands: experimental strategy and results from a new European initiative, Plant Soil, 228, 131-145, 2001a.
Sutton, M. A., Nemitz, E., Erisman, J. W., Beier, C., Butterbach Bahl, K., Cellier, C., de Vries, W., Cotrufo, F., Skiba, U., Di Marco, C., Jones, S., Laville, P., Soussana, J. F., Loubet, B., Twigg, M., Famulari, D., Whitehead, J., Gallagher, M. W., Neftel, A., Flechard, C., Herrmann, B., Calanca, P. L., Schjoerring, J. K., Daemmgen, U., Horvath, L., Tang, Y.S., Emmett, B. A., Tietema, A., Peñuelas, J., Kesik, M., Brueggemann, N., Pilegaard, K., Vesala, T., Campbell, C. L., Olesen, J. E., Dragosits, U., Theobald, M. R., Levy, P., Mobbs, D. C., Milne, R., Viovy, N., Vuichard, N., Smith, J. U., Smith, P.E., Bergamaschi, P., Fowler, D., and Reis, S.: Challenges in quantifying biosphere-atmosphere exchange of nitrogen species. Environ. Pollut. 150, 125-139, 2007.

Sutton, M. A., Erisman, J. W., Dentener, F., and Moeller, D.: Ammonia in the environment: from ancient times to the present, Environ. Pollut., 156, 583-604, 2008a.

Sutton, M. A., Nemitz, E., Theobald, M. R., Milford, C., Dorsey, J. R., Gallagher, M. W., Hensen, A., Jongejan, P. A. C., Erisman, J. W., Mattsson, M., Schjoerring, J. K., Cellier, P., Loubet, B., Roche, R., Neftel, A., Herrmann, B., Jones, S. K., Lehman, B. E., Horvath, L., Weidinger, T., Rajkai, K., Burkhardt, J., Löpmeier, F. J., and Dämmgen, U.: Dynamics of ammonia exchange with cut grassland: Strategy and implementation of the GRAMINAE Integrated Experiment, Biogeosciences, 6, 309-331, 2009a, http://www.biogeosciences.net/6/309/2009/.

Sutton, M. A., Nemitz, E., Milford, C., Campbell, C., Erisman, J. W., Hensen, A., Cellier, P., David, M., Loubet, B., Personne, E., Schjoerring, J. K., Mattsson, M., Dorsey, J. R., Gallagher, M. W., Horvath, L., Weidinger, T., Meszaros, R., Dämmgen, U., Neftel, A., Herrmann, B., Lehman, B. E. Flechard, C., and Burkhardt, J.: Dynamics of ammonia exchange with cut grassland: Synthesis of results and conclusions, Biogeosciences Discuss., 6, 11211184, 2009b.

Sutton, M. A., Reis, S., and Baker, S. M. H. (Eds.): Atmospheric ammonia: detecting emission changes and environmental impacts, Springer, 2009c.

Sutton, M. A., Simpson, D., Levy, P. E., Smith, R. I., Reis, S., van Oijen, M., and de Vries, W.: Uncertainties in the relationship between atmospheric nitrogen deposition and forest carbon sequestration, Global Change Biol., 14, 2057-2063, doi:10.1111/j.1365-2486.2008.01636.x, 2008b.

Thomas, R. M., Trebs, I., Otjes, R., Jongejan, P. A. C., ten Brink, H., Phillips, G., Kortner, M., Meixner, F. X., and Nemitz, E.: An automated analyzer to measure surface-atmosphere exchange fluxes of water soluble inorganic aerosol compounds and reactive trace gases, Environ. Sci. Technol., 43, 1412-1418, 2009.

van Hove, L. W. A., Heeres, P., and Bossen, M. E.: The annual variation in stomatal ammonia compensation point of rye grass (Lolium perenne L.) leaves in an intensively managed grassland, Atmos. Environ., 36, 2965-2977, 2002.

Whitehead, D. C., Lockyer, D. R., and Raistrick, N.: The volatilization of ammonia from perennial ryegrass during decomposition, drying and induced senescence, Ann. Bot., 61, 567-571, 1988.

Whitehead, J. D., Twigg, M., Famulari, D., Nemitz, E., Sutton, M. A., Gallagher, M. W., and Fowler, D.: Evaluation of laser absorption spectroscopic techniques for eddy covariance flux measurements of ammonia, Environ. Sci. Technol., 42, 20412046, 2008. 
Wilson, K., Goldstein, A., Falge, E., Aubinet, M., Baldocchi, D., Berbigier, P., Bernhofer, C., Ceulenmans, R., Dolman, H., Field, C., Grelle, A., Ibrom, A., Law, B. E., Kowalski, A., Meyers, T., Moncrieff, J., Monson, R., Oechel, W., Tenhunen, J., Valentini, R., and Verma, S.: Energy balance closure at FLUXNET sites, Agr. For. Meteor., 113, 223-243, 2002.
Wyers, G. P., Otjes, R. P., and Slanina, J.: A continuousflow denuder for the measurement of ambient concentrations and surface-exchange fluxes of ammonia, Atmos. Environ., 27, 2085-2090, 1993. 